\title{
ADVANCEMENTS IN GEOMORPHIC MINE RECLAMATION DESIGN APPROACH, WYOMING ABANDONED MINE LAND, LIONKOL COAL MINING DISTRICT, SWEETWATER COUNTY, WYOMING ${ }^{1}$
}

\begin{abstract}
Harold J. Hutson, ${ }^{2}$ and Robert W. Thoman
Abstract: Following the successful pioneering of Natural Regrade ${ }^{\mathrm{TM}}$ technology for geomorphic surface mine reclamation efforts in WY in 2007, the Wyoming AML Division and their Project Engineer, BRS, Inc. of Riverton, WY, applied this surface reclamation approach to the Lionkol Project located near Rock Springs, WY, in Sweetwater County.

The Lionkol Project is located within a historic coal mining district that was extensively mined underground from the early 1900's through the 1940's, then followed by open pit mining that continued into the early 1970's. The project was completed in four phases over a 6-year period, with the final phase completed in the fall of 2013. The project reclaimed 320 acres of intensely disturbed mine lands including 5 miles of degraded mainstream drainages.

The Lionkol Project fully implemented methods in geomorphic mine land reclamation to achieve a sustainable reclaimed landscape that blends with native topography and provides for long-term erosional stability. The project addressed hazards and environmental degradation related to historic surface and underground coal mining while preserving historic features. Design challenges, modifications in design approach, and innovations are discussed as well as performance evaluations of the channels and a summary of lessons learned for future efforts.
\end{abstract}

Additional Key Words: Natural Regrade, erosion, channel stability

${ }^{1}$ Presented at the 2013 National Meeting of the American Society of Mining and Reclamation, Laramie, WY. Reclamation Across Industries June 1 - 6, 2013. R.I. Barnhisel (Ed.) Published by ASMR, 1305 Weathervane Dr., Champaign, IL 61821.

${ }^{2}$ Harold J. Hutson, P.E., P.G., Senior Geological Engineer, BRS, Inc., 1130 Major Ave., Riverton, WY 82501; and Robert W. Thoman, P.E., Project Engineer, BRS, Inc. 1130 Major Ave., Riverton, WY 82501.

Journal American Society of Mining and Reclamation, 2017 Volume 6, Issue 2 pp 51-83

DOI: http://doi.org/10.21000/JASMR17020051 


\section{$\underline{\text { Introduction }}$}

Historic coal mining in Sweetwater County, WY, has left mining features including pits, highwalls, and degraded channels. Reclamation of these features is being addressed by the Wyoming Department of Environmental Quality (WDEQ) Abandoned Mine Lands (AML). The primary goal of mine reclamation is to remove hazards impacting public safety. In past efforts, cost effectiveness motivated reclamation methods and procedures. From this, traditional reclamation emerged with continuous, constant-grade slopes featuring cross-slope ditching and large grade-control structures. Considerations such as re-establishing pre-mine topography, developing a dynamic system, or focusing on aesthetics generally did not make it through the design phase due to their perceived initial cost.

Traditional reclamation methods seemed satisfactory in addressing mine pits and highwalls. Material costs, such as rock riprap, were high, but were offset by the low dirt moving costs. However, if sediment movement occurred after construction, the cross-slope ditches would silt-in, often resulting in ditch and slope failures. Consequently, significant maintenance was necessary, with additional costs that were not figured into the original design.

Traditional methods were less successful for reclaiming degraded channels. Straight channels with flat grades required large rock structures for grade adjustments and energy dissipation. Sites with large grade differences required a significant amount of rock, thereby increasing costs. Stability was difficult to achieve in a channel segmented by rock structures, and continued maintenance was often required. The straight, trapezoidal channels lined with rock drop structures were not aesthetically pleasing and did not blend into the existing topography.

Thus, a method of mine reclamation was sought that would place more emphasis on the premine topography, address aesthetics, blend in with the surrounding native areas, and reduce long term maintenance. Geomorphic reclamation provided a solution to the pitfalls of traditional reclamation. Some of the benefits of a geomorphic design include low maintenance costs, enhanced viewshed, and a natural appearing surface.

This case study presents the results of a multi-phase reclamation project in the Lionkol drainage of Sweetwater County, WY. The design approach and considerations evolved throughout the 6-year project. Evaluation of the reclamation was performed on the completed phases before the subsequent phase was designed. This led to significant developments in the design 
assumptions and how they affected the stability of the final surface. Although specific to the rainfall, runoff patterns, and soils of Sweetwater County, WY, the results of this study give a better understanding of mine reclamation and the application of geomorphic design approach. Practitioners will gain valuable knowledge from years of monitoring data as well as anecdotal evidence on performance and maintenance.

\section{Background}

A significant contributor to geomorphic reclamation was the Carlson Natural Regrade ${ }^{\mathrm{TM}}$ (NR) software with the GeoFluv ${ }^{\mathrm{TM}}$ fluvial geomorphic landform design. NR was developed for mine reclamation. Application of the geomorphic design principles in this case study were accomplished utilizing the NR modeling software.

NR is a software package that allows reclamation designers to create geomorphically stable, diverse, and naturally appearing landform designs that promote vegetative growth and function similar to a native system. The geomorphic design approach seeks to mimic the native topography while providing a sustainable landform that requires little to no continued maintenance (Walker, 2013). The NR design includes slopes that transition from convex to concave profiles, concave drainage profiles, multiple small drainage basins that break up the surface topography, and meandering channels that reduce gradients for improved stability. When combined, these design features create a variable terrain that is aesthetically pleasing and natural in appearance.

NR works in the AutoCAD platform and requires an existing ground surface model. Design inputs under the Settings tab require site-specific values. Once channels are input into the program, specific channel variables can be entered in the Channel Settings dialogue box. By adjusting these input parameters, different channel configurations can be obtained to match site-specific geomorphic features.

The NR channel stability analysis is based on incipient particle motion, where the shear stress is calculated from the tractive force of the flowing water. NR recommended shear stress limits are 1.0 pound per square foot (psf) for the 2-year (yr), 1-hour (hr) storm event, and 1.5 psf for the 50yr, 6-hr storm event. This is based on the shear stress required to initiate movement for loose, finegrained soils. The shear stress is related to the channel geometry and storm flows as follows:

$$
\tau=\gamma \mathrm{dS}
$$


where $\tau=$ hydraulic shear stress; $\gamma=$ unit weight of water; $d=$ flow depth; and $S=$ the friction slope (approximated by the channel bed slope). NR calculates channel width internally; therefore, reductions in shear stress are obtained by reducing the channel slope or reducing the flow depth.

\section{Study Area}

The Lionkol drainage is located in a historic coal mining district in Sweetwater County, WY, approximately one mile, northeast of Rock Springs along the Lionkol road. The area is considered a high desert, with an elevation of $6500 \mathrm{ft}$. Annual precipitation for Rock Springs, WY, is 8.5 in., with runoff generally occurring in the spring and fall. The Lionkol drainage can be characterized by fine-grained alluvium consisting of a silty-sand material with sandstone outcrop. Soil quality is generally poor with elevated levels of salts and Boron.

\section{$\underline{\text { Study Results }}$}

Four reclamation phases, spanning 6 years, were completed in the Lionkol drainage as part of the WDEQ AML reclamation project. The first phase of the project was initiated in fall 2008, and the final phase was completed in fall 2013. Each phase applied varying degrees of geomorphic design. Design approach evolution is discussed in the subsequent sections.

The projects were broken down into four construction phases. The four phases, in order of construction, include:

- $\quad$ Reliance No. 11 North and South Pits (2008)

- $\quad$ Reliance No. 3 and Lionkol Pits (Main, Lower Spoils \& Lower Pit) (2009)

- $\quad$ Lionkol Drainage (2012)

- $\quad$ Lionkol West (2013)

An overview map of the Lionkol drainage is shown in Fig. 1.

$\underline{\text { Reliance No. } 11 \text { North and South Pits }}$

The Reliance No. 11 North and South Pits phase involved reclaiming two separate open pit coal mine areas using a combination of geomorphic and traditional reclamation techniques. This was the first Wyoming AML project designed and bid incorporating the geomorphic design approach. The basins for the North and South Pits are large, and the overall basin gradients and total relief are high. As a result, the simulated shear stresses are above the NR recommended limits. In order to reduce the shear stresses, traditional storm water runoff structures and concepts 
were incorporated with the geomorphic-designed channels to decrease flow rates.

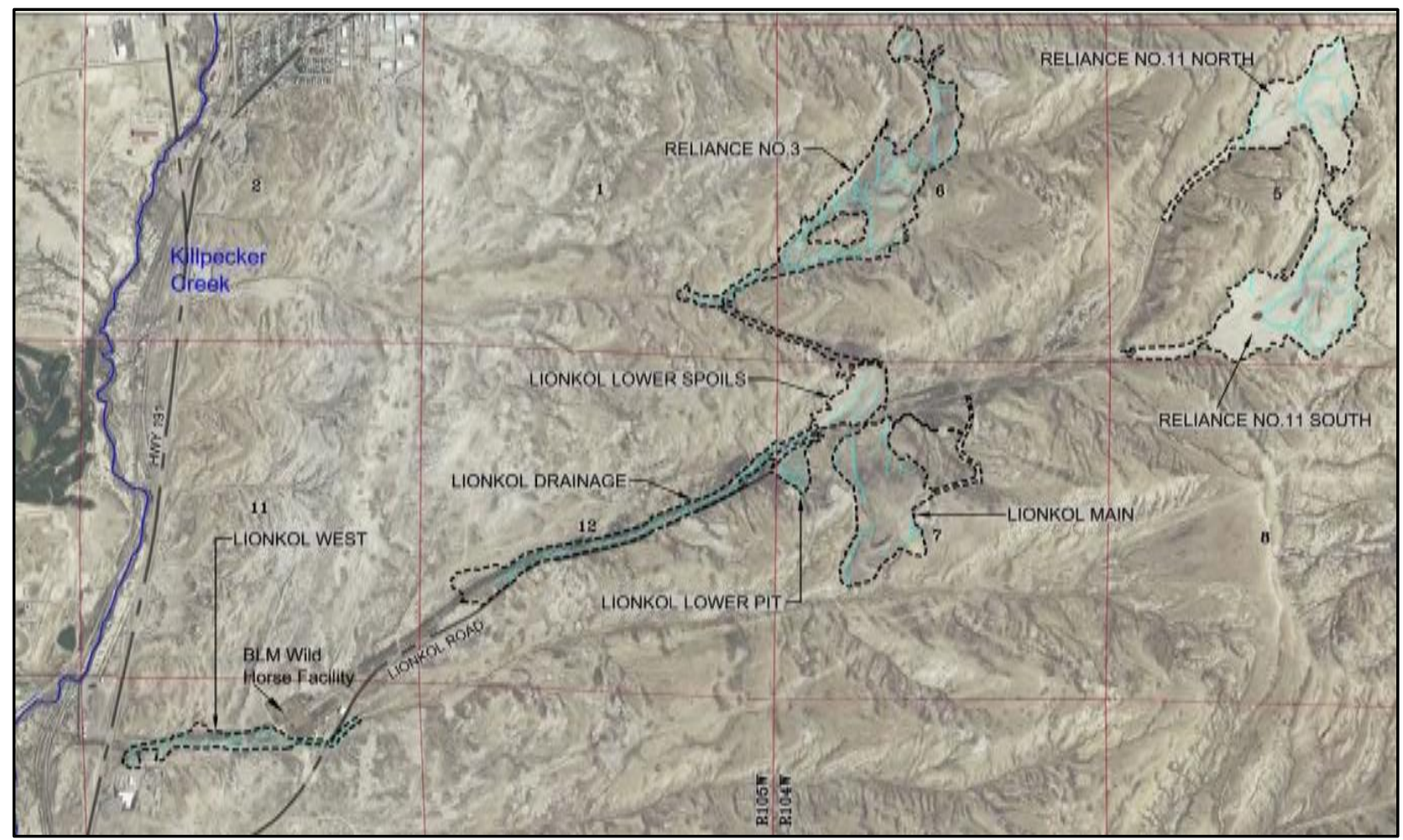

Figure 1. Overview of the Lionkol drainage and project phases. The project area is located just northeast of Rock Springs, WY.

Four surface-water attenuation impoundments were constructed for this project: two at the North Pit and two at the South Pit. In addition to attenuating flow within the Reliance No. 11 project area, the impoundments also decrease off-site discharge. This was important since the pre-reclamation surface completely retained site runoff at both the North and South Pit sites. Reintroducing these flows into a hydrologic system that had not been subject to the flows since the early 1970's would have been potentially damaging to downstream channel sections. Additionally, the Lionkol drainage had not been reclaimed and was experiencing extreme downcutting. Increasing the contributing area within the drainage basin and the resultant increase in storm flows would have increased the potential for downstream erosion. Thus, detaining runoff on-site was necessary to minimize off-site degradation.

Five separate basins were modeled for the Reliance No. 11 North. The total basin area for the North project is 27.5 ac. The basin is steep, with an average channel relief of $40 \mathrm{ft}$. This is a contributing factor to the initial high shear stresses modeled for the project area, and lead to the 
implementation of additional design controls. Surface-water attenuation impoundments were used to limit surface runoff and maintain channel shear stresses within the recommended range. After design of additional storm water controls, only short sections of the channel reaches exceeded the recommended shear stresses.

Two surface-water impoundments were constructed on the Reliance No. 11 North site, as shown in Fig. 2. Both impoundments provide runoff attenuation to downstream reaches. Pond 2 does not discharge and the Main Pond provides peak flow attenuation with a lag time of approximately 30 minutes. Two riprap-erosion-control drop structures were installed on the North Pit outlet channel to compensate for the vertical differential between spoils in the disturbed mine site and the native outlet channel. For this channel portion, a traditional 12-ft flat bottom channel was constructed with a meandering alignment for a smooth transition into the drop structures. In addition, a riprap-grade-control structure was installed at the outlet of each of the impoundments to protect the impoundment from failure in the event that the outlets were overtopped.

Two separate basins were modeled for the Reliance No. 11 South design, shown in Fig. 3. The area draining into the Main Pond was constructed as two separate basins. The total basin area for the South project is 80.4 ac. Relief in the south basin is high, with an average of $66 \mathrm{ft}$. This is a contributing factor to the initial high shear stresses modeled for the project area. As a result, flows were contained in Pond 2, a pre-existing feature created by spoils placement that blocked the drainage into the head of the main channel. Through the majority of the channel, shear stresses fell below the design ranges. Notably, the channels that exceed the recommended shear stress values are characterized by large contributing areas and corresponding peak discharges. The South Spoils area was modeled separately due to a drainage divide.

The South Spoils (Fig. 3) was created by mine waste being dozed over the edge of a steep natural escarpment. This resulted in an over-steepened fill slope that covered a steep native drainage of primarily exposed bedrock. The proposed reclamation design entailed excavating this area to approximate pre-mine topography. In practice, only a portion of the design was constructed to grade, as native bedrock was exposed prior to achieving the design grades. The constructed surface was adjusted in the field for exposed bedrock. As such, the geomorphic design parameters were not met, and the design provided only a loose framework for long-term evaluation of the existing surface. 


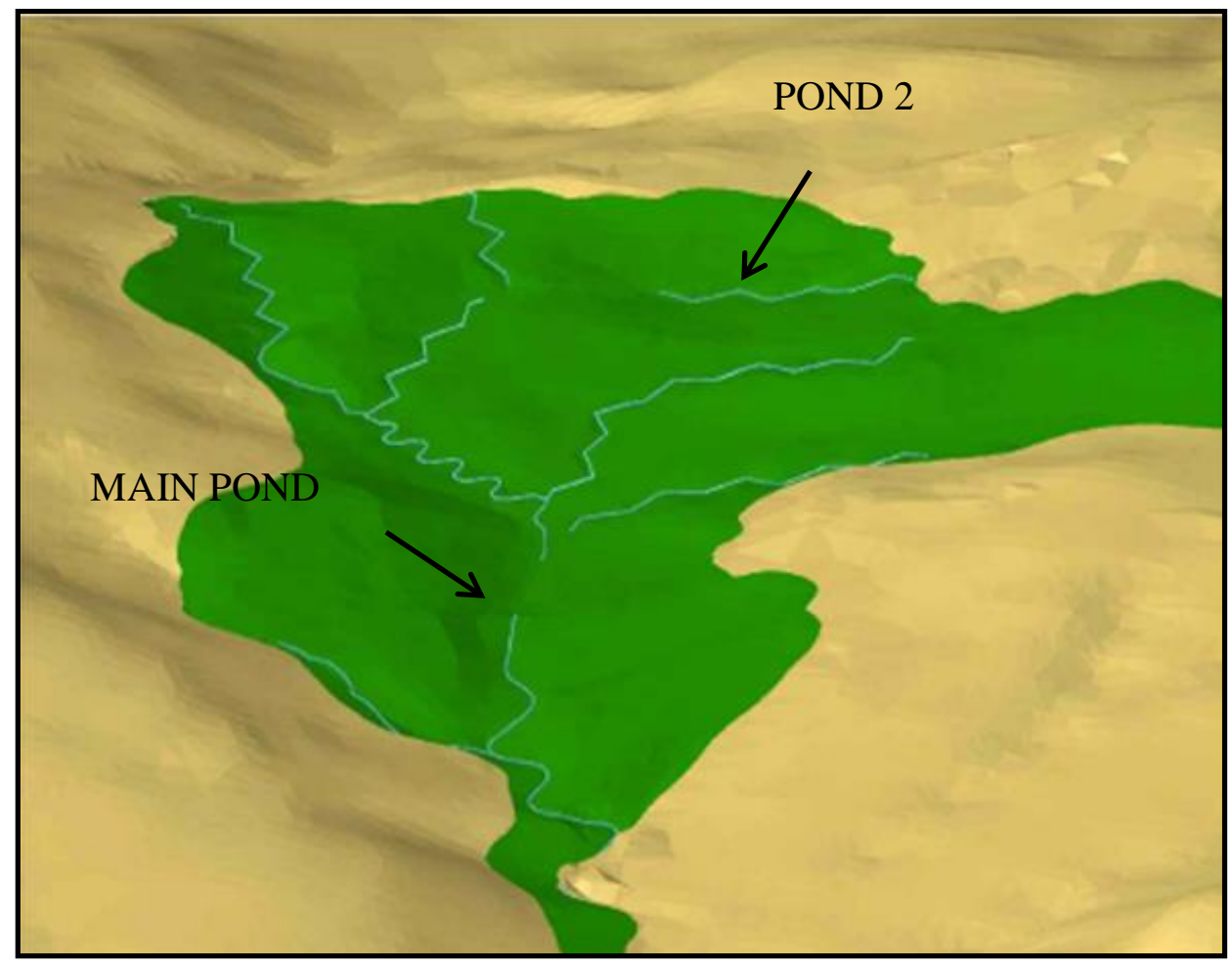

Figure 2. Reliance No. 11 North geomorphic design using 3D rendering. Two surface water impoundments were utilized for water attenuation.

For the Reliance No. 11 Pits project, a critical-design criteriona was achieving the recommended shear stresses. Shear stresses were minimized by incorporating traditional reclamation structures and concepts to decrease flow quantities and velocities. Traditional structures included runoff attenuation impoundments, a traditional flat bottom channel, and riprap erosion control structures. The traditional design features were combined with the 3D line work in AutoCAD to create the final design product. By incorporating the traditional storm water controls, the shear stresses were reduced to, or near, the recommended values.

\section{$\underline{\text { Reliance No. } 3 \text { and Lionkol Main Pits }}$}

The Reliance No. 3 and Lionkol Main Pits phase addressed two separate coal mine areas primarily using geomorphic reclamation with a minimal amount of traditional reclamation techniques. The basic conceptual approach was to restore each of the disturbed areas to approximate pre-mine contours and drainage configurations. When the initial designs were modeled for some of the project areas, the design shear stresses were well in excess of the recommended values. In multiple project areas, especially the Reliance No. 3 Pit, the designed main channel grades, basin areas, and alignments were very close representations of the pre-mine 
topography. The model likely generated a surface that was more stable than the pre-mine surface, as the channel sinuosity used in the design was higher than had been observed in the project region. Local areas of rocky and/or clay material were thought to influence the pre-mine surface.

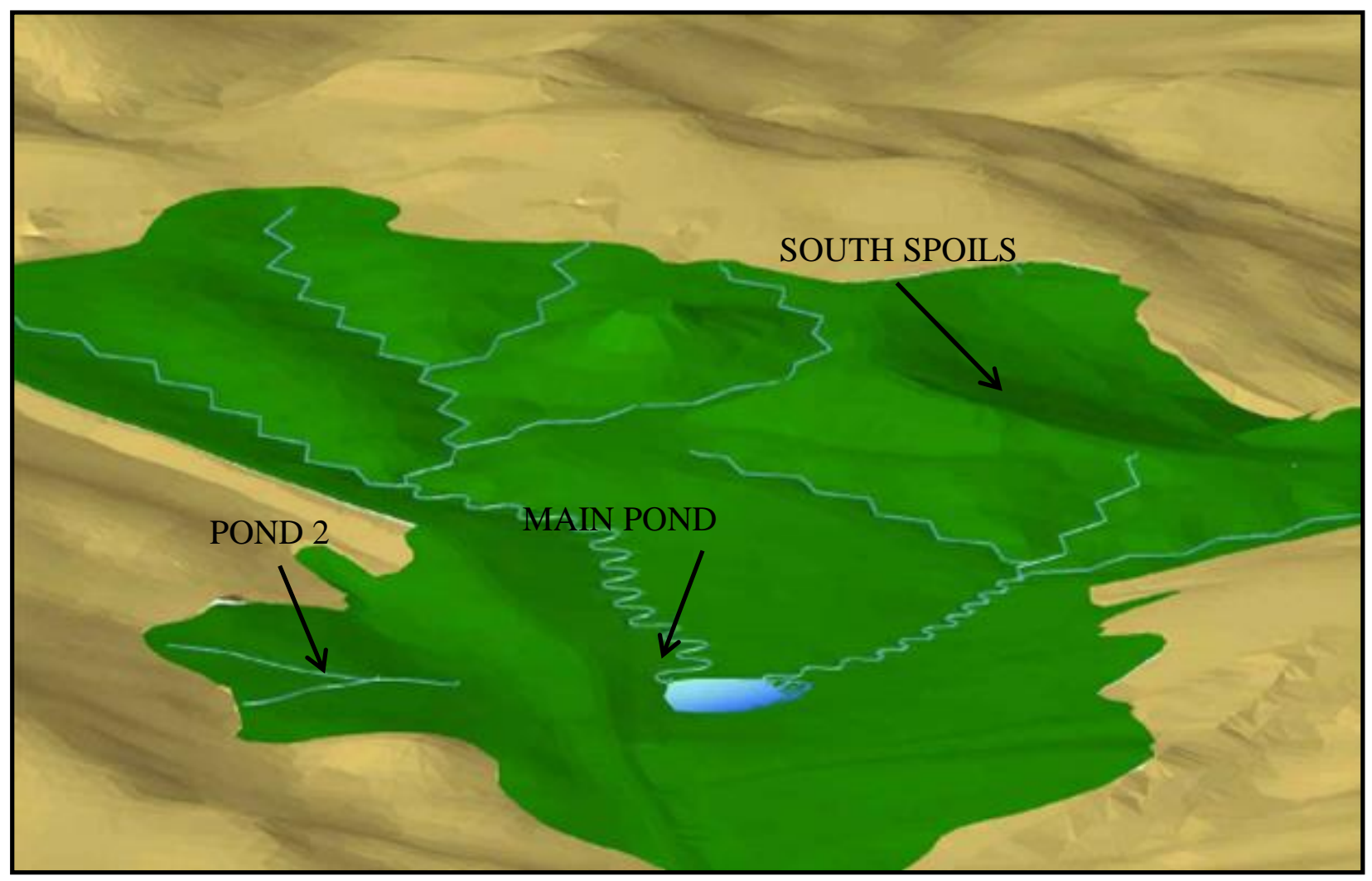

Figure 3. Reliance No. 11 South geomorphic design with 3D rendering. The Main Pond was a pre-existing feature that was retained in the design to trap sediment.

Four separate basins were modeled for the Reliance No. 3 area design, as shown in Fig. 4. The Main Valley basin drains the largest portion of the pit area. A large tributary basin to the south of the main valley is shown as Valley 2. These two drainages join at the east end of the pit area, where they are conveyed through a short section of well-vegetated, stable channel that was not disturbed by mining or reclamation activities. The combined flows are then conveyed off site through the Outlet Channel. Additional small grading areas include the North Pit and the North Spoils. 


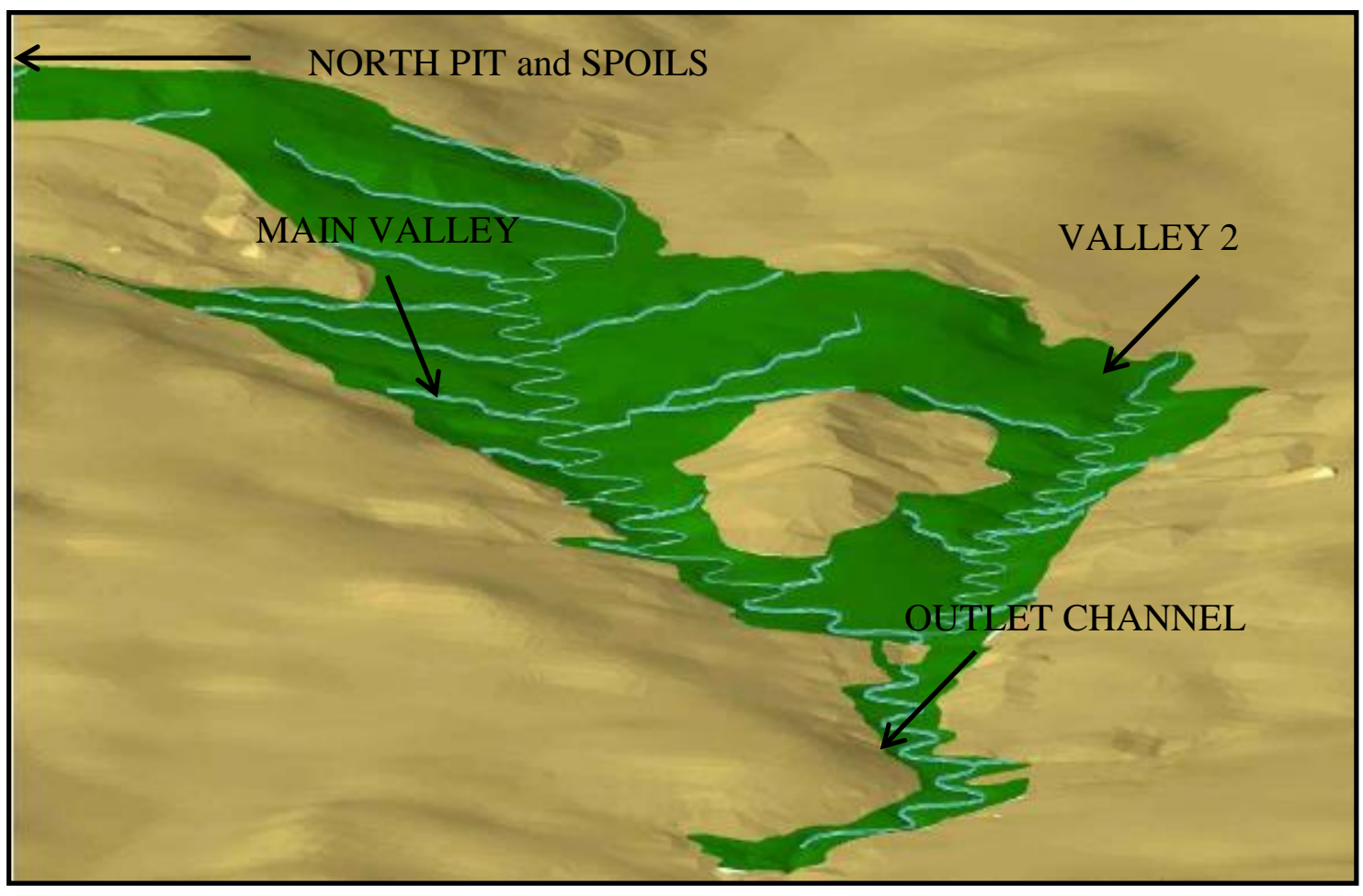

Figure 4. Reliance No. 3 geomorphic design with 3D rendering. The geomorphic design mimicked the natural topography, even though the stability criteria was exceeded.

The basin area for the Main Valley is 223 ac. The Main Valley drainage is over a mile long with approximately $365 \mathrm{ft}$ of relief and 109 ac of contributing area. Fourteen tributary channels are connected to the main channel, with an additional three secondary tributaries adding to the dendritic drainage pattern. Many of these channels exceeded the recommended shear stress values. High shear stresses are primarily related to steep channel gradients, low drainage density, and large contributing areas.

Valley 2 is similar to the Main Valley at just under a mile long with approximately $300 \mathrm{ft}$ of relief. Valley 2 has a basin area of 101 ac, with an additional 109 ac of contributing area. Nine tributary channels enter the Valley 2 main channel. The channel shear stress ranges for the smaller tributary channels are at, or below, the recommended shear stress values, while the main channel and larger tributaries are greater than the recommended maximum shear stress values.

The local basin area for the Outlet Channel is 86 ac, which includes one tributary channel draining 65 ac from the south. Another 370 ac of contributing area is added from the Main Valley and Valley 2 basins. At the time the designs were completed, this was the largest basin area 
conveyed by a geomorphic designed channel in a Wyoming AML project. The Outlet Channel basin is approximately 1,400 ft long with $40 \mathrm{ft}$ of relief. The channel shear stresses are nearly double the recommended shear stress values, and the difference between the high to low shear stress values is minimal. The runoff experienced by this channel is driven by the contributing area flows.

The local basin area for the North Pit is 3.7 ac. The reclamation design included a main channel with one tributary channel draining 1.3 ac from the south. This drainage is a small, upland area. The North Pit basin is approximately $588 \mathrm{ft}$ long with $39 \mathrm{ft}$ of relief. The channel shear stresses are less than the maximum recommended shear stress values due to the small basin areas.

The local basin area for the North Spoils is 4.5 ac. The total contributing area entering the North Spoils basin is 12.9 ac, which includes the North Pit separated by a reach of undisturbed channel. The North Spoils basin is approximately $484 \mathrm{ft}$ long with $54 \mathrm{ft}$ of relief. The channel shear stresses are in excess of the recommended shear ranges due to the contributing basin area (larger flows).

Three separate areas were reclaimed as part the Lionkol Main Pit reclamation portion: The Main Pit, the Lower Pit, and the Lower Spoils (Fig. 5). The Lionkol Main Pit area was a "mountain top strip" type of open pit mine with over-steepened spoils pushed off both the north and south ends of the pit. The reclamation design for this area was modeled as 10 distinct basins due to the upland nature of the site, without connecting channels. The Main Pit is approximately 54 ac, with individual design basins averaging $5.4 \mathrm{ac}$. The design attempted to reclaim the site to approximate pre-mine contours by removing the spoils that had been dozed off the top of the ridge, and relocating the spoils in the pit (Fig. 6). During the excavation of the spoils, the pre-mine surface was exhumed on both the north and south sides, exposing native sandstone rock outcrops. As a result, three of the channels were not built to the design grades over portions of their alignment. These channels had steep sections of sandstone rock, with the design grades constructed above and below the bedrock sections. Most of the channel shear stress ranges are in excess of the recommended values. For these basins, the high shear stresses are caused by steep channel gradients. However, based on the small average basin size, the total volume of flow is typically low, and as such the erosional ability of the flows is minimal. 


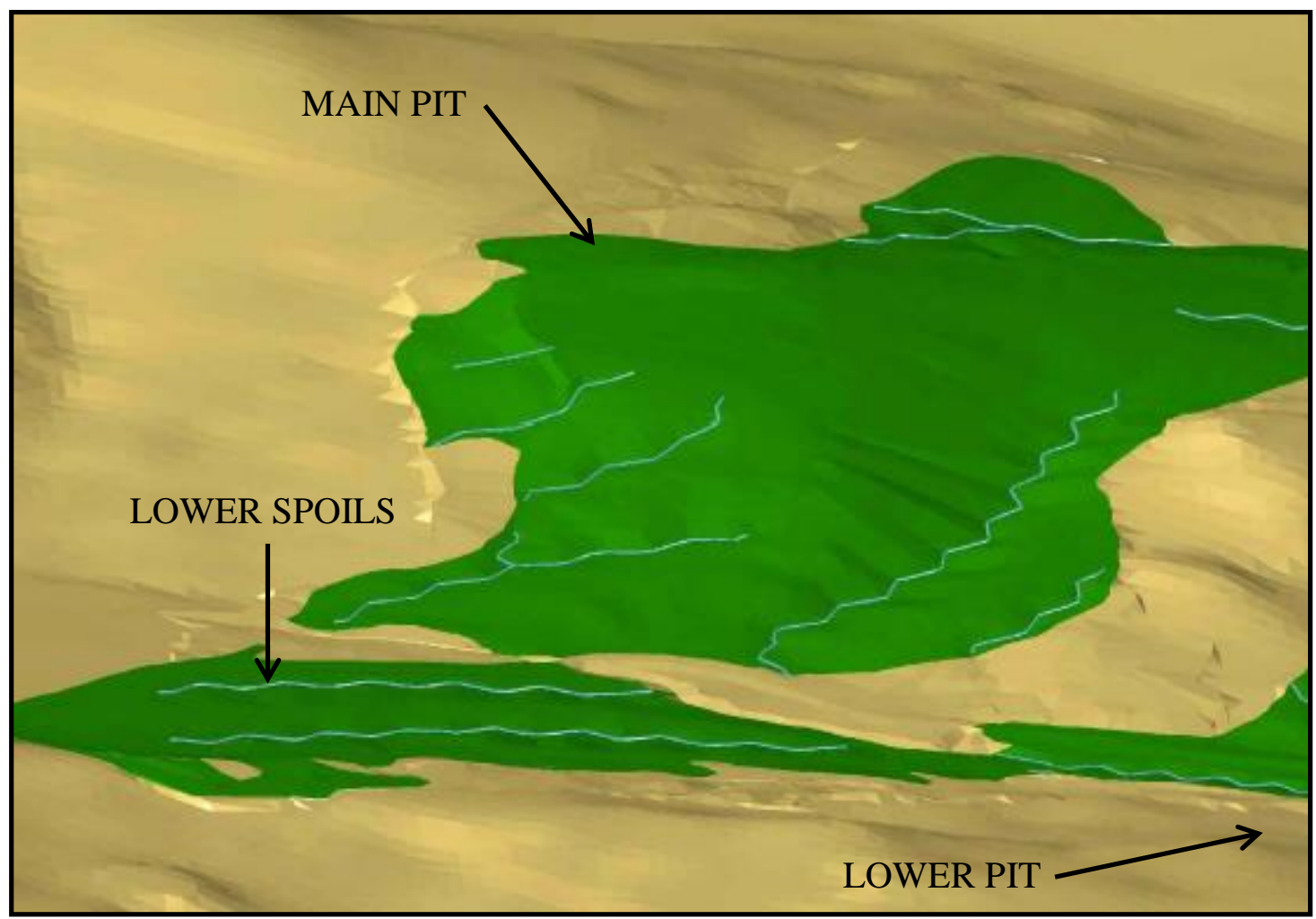

Figure 5. Lionkol Main Pits geomorphic design shown with 3D rendering. The design had to be amended to match the native surface, due to sandstone outcrops exposed under the spoils pile.

The Lower Pit was backfilled with material from the Lower Spoils, creating a single basin draining to a small sediment pond built against the Lionkol road. A 24-in culvert conveys the flow under the Lionkol road, where it drains into the Lionkol drainage. The Lower Pit is approximately $5 \mathrm{ac}$ with a basin length of $700 \mathrm{ft}$ and relief of $48 \mathrm{ft}$. As a result, the Main channel gradient, and its two tributaries, are $6 \%$ at the flattest, and increase from there up to a maximum of $18 \%$. The shear stress ranges for the channels are in excess of the recommended stability criteria. The Main channel is characterized by a flood-prone maximum shear stress of $5.28 \mathrm{psf}$, the highest shear stress noted on the project sites. For these basins, the high shear stresses are caused by steep channel gradients. However, based on the small average basin size, the flow is low and the erosion potential minimal. 


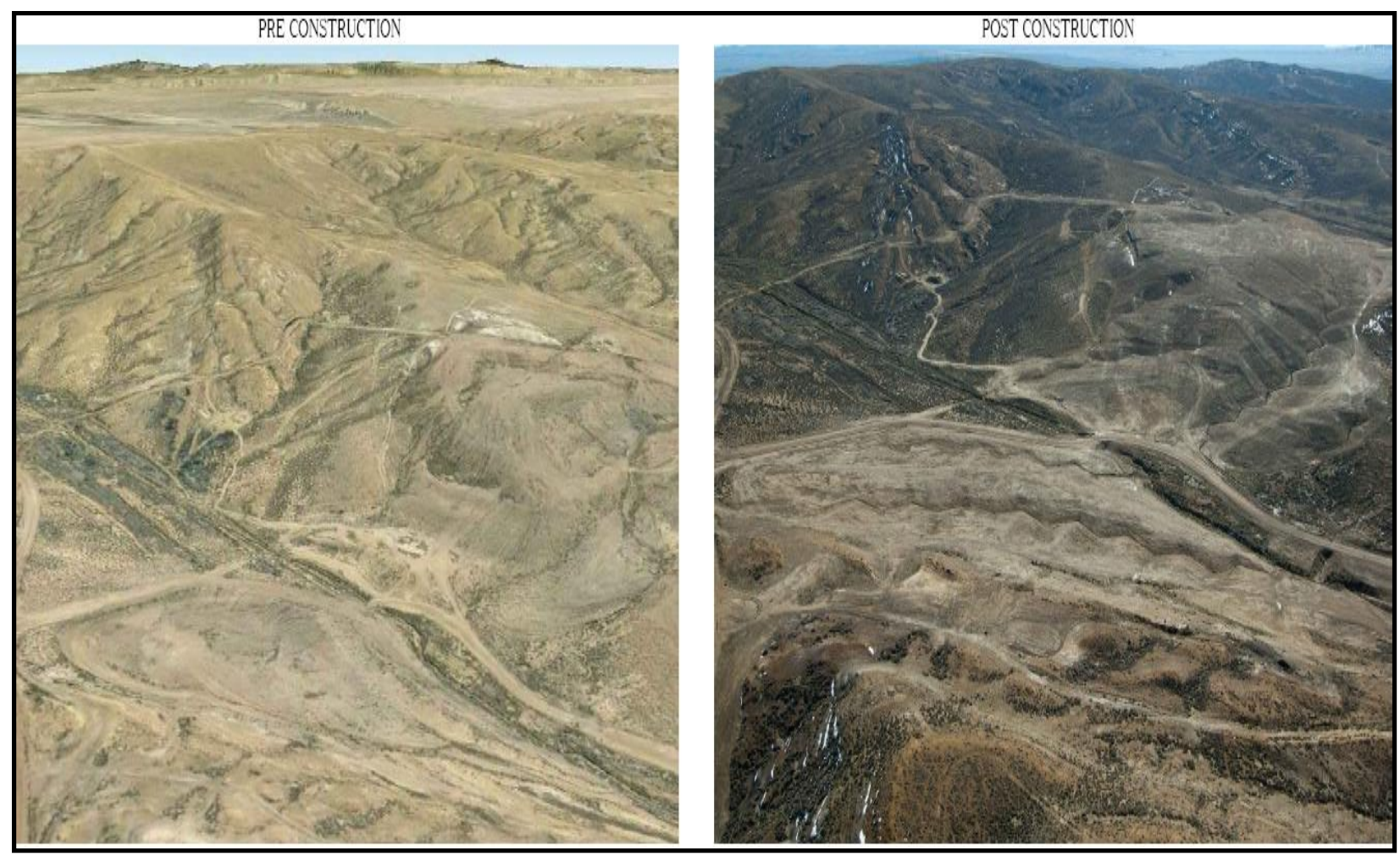

Figure 6. Lionkol Main Pits images before and after construction. The Main Pit was a "mountain top" mine, where the top of the hill was excavated and pushed over the sides.

The Lower Spoils were excavated to approximate pre-mine contours and shaped into two separate basins flowing into the Lionkol drainage. The Lower Spoils is divided into two basins and comprises $12 \mathrm{ac}$. The basin lengths range from approximately $780 \mathrm{ft}$ to $1180 \mathrm{ft}$ with relief of $42 \mathrm{ft}$ to $74 \mathrm{ft}$, respectively. The channel gradients for the two long upland basins range from $6 \%$ to $8 \%$. The shear stress ranges for the channels meet the recommended values. While the channel gradients are moderately steep, the flow is low and the erosion potential minimal. Performance to date indicates that the basins are stable.

Discussions with the NR software developer to address concerns with high shear stresses and how they affect the channel stability led to a new understanding. NR was intended to develop a design that mimics the surrounding native system as closely as possible. If a native channel is found to be erosive due to factors such as relief, gradient, site materials, and precipitation, constructing non-erosive reclaimed channel reaches may upset the natural equilibrium of the overall channel. If the reclaimed channel is constructed with significantly higher stability than the incoming and outgoing native channel reaches, deposition is likely to occur in the design reach. 
Likewise, the native downstream reach could experience erosion due to the lack of sediment load from the overly stable reclaimed reach. Upon encountering the less stable native channel, the flow would accelerate and begin to erode the native channel in an effort to achieve balance between the flow energy and the ability to transport sediment. In support of this line of thought, while incipient particle motion indicates the size of particles that can be put into motion by a shear stress of a particular magnitude, it provides no information on the distance that a particle may be transported or the quantity of particles of a similar size that may be transported since there may be factors which would affect the amount of erosion that a channel may experience. Excessive quantities of materials transported large distances would be perceived as channel failure due to erosion, but a moderate, even progress of sediment through the system would be perceived as normal and healthy channel development. As a result, if the reclaimed reaches are designed to match the native channel grades, cross sections, and stability parameters, in theory sediment transport through the site should be similar as well.

Ultimately, the goal was to develop a design, which matches the native system as closely as possible. The Wyoming AML understood the risks in proceeding under these assumptions, and was willing to do so to advance the application and understanding of the geomorphic design methods for future projects. Wyoming AML understood that if the channels failed with unacceptable levels of erosion, remedial work may be necessary. To date, this design determination has proved to be adequate. Recent site inspections indicate that roughly $80 \%$ of the constructed channel reaches do not have unacceptable levels of erosion occurring on site.

\section{Lionkol Drainage}

The Lionkol Drainage Project was completed in the fall of 2012 to regrade a reach of the Lionkol drainage that was confined between the historic railroad grade and the mine haul road. Over time, the channel became incised due to the straightened alignment and the lack of a floodplain, which was encroached upon by the rail grade and the road. The incised channel was close to the existing road, creating steep and dangerous banks along the road shoulder, and erosional cuts crossed the road, making it impassable. The goal of the project was to re-establish the channel and floodplain to a stable configuration resembling the pre-mine conditions.

The design trimmed the steep banks and raised the channel bottom. Excess material from the excavation was used to construct an embankment at the downstream end of the project, which 
balanced the earthworks. The embankment and associated impoundment were necessary to raise the channel elevation and reduce the channel slope. The embankment serves as a grade control structure at the downstream end of the channel reconstruction

Two basins were used to model the Lionkol drainage, Lionkol Upper and Lionkol Lower, as shown in Fig. 7. The channel is continuous through this reach, but required two basins to manipulate the channel design around cultural features. Some of the design work was completed in AutoCAD to connect the channels between the two basins. The valley length through the regraded section is approximately 1.2 miles long with an elevation drop of $120 \mathrm{ft}$. The designed

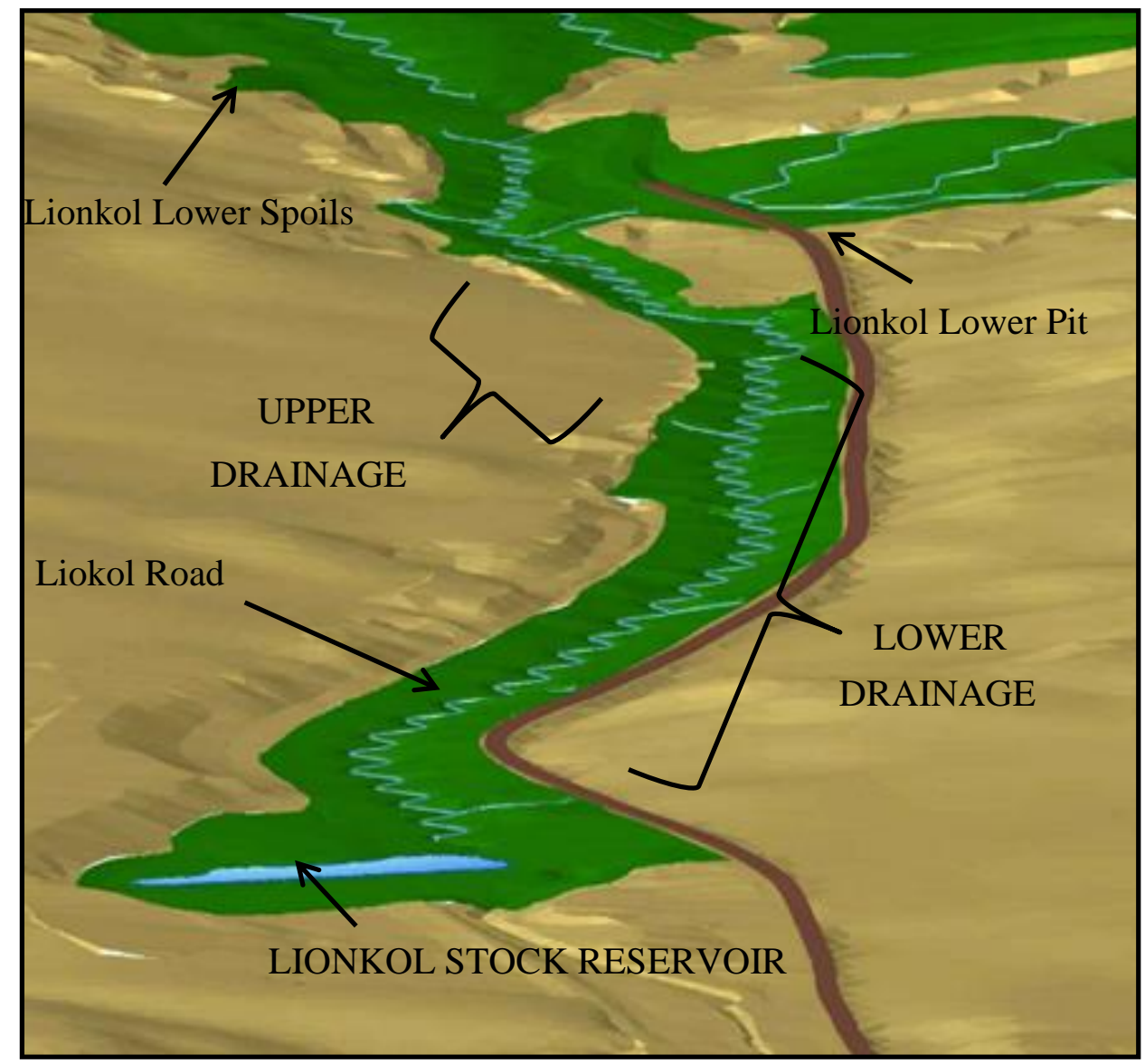

Figure 7. Lionkol drainage design with 3D rendering showing design areas. The project was split into two drainages, to design around cultural features.

section ends at the Lionkol Stock Reservoir (Fig. 8). The purpose of the reservoir is to assist the City of Rock Springs in limiting flood flows in the downtown area. 


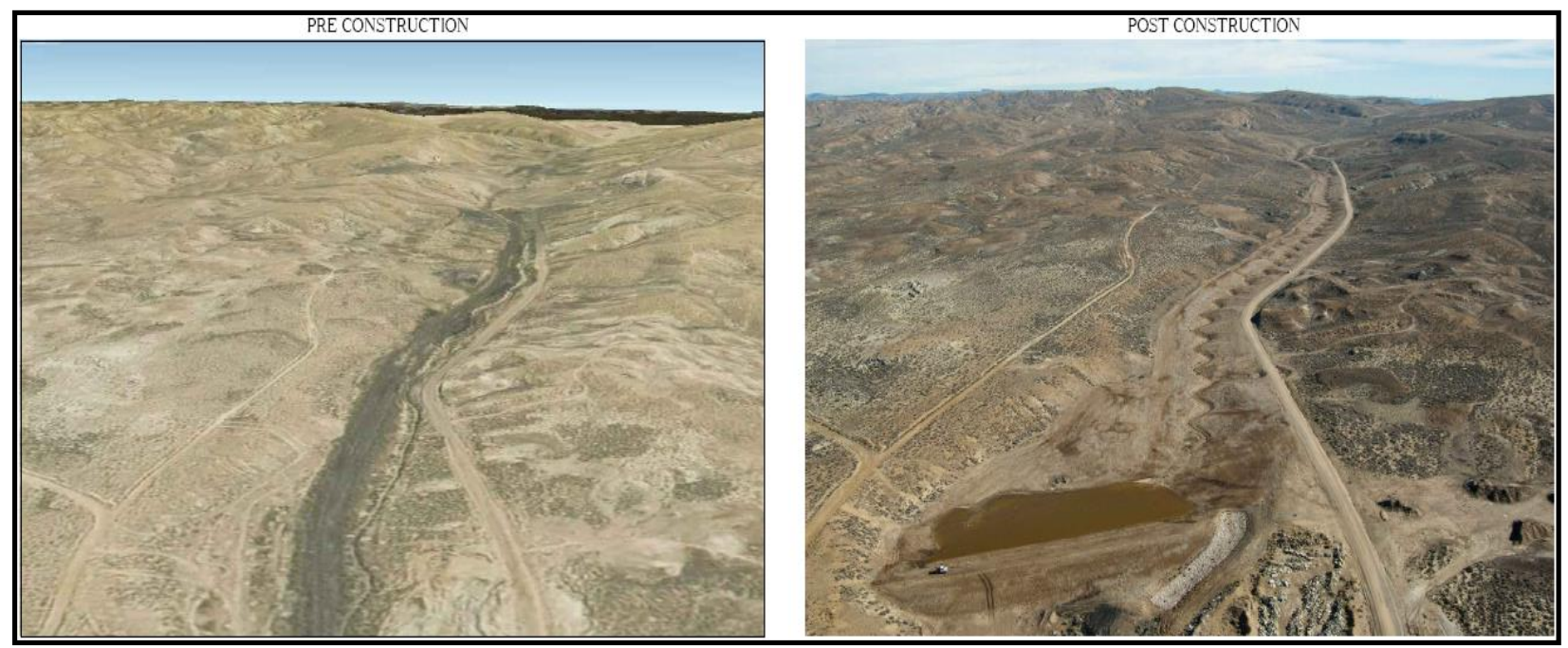

Figure 8. Images of the Lionkol drainage before and after construction. The design channel terminates at the Lionkol Stock Reservoir.

Twelve side tributaries are connected to the two basins. Five culverts were installed through the main access road to connect side tributaries with the main channel and reduce erosion of the road. Shear stresses are slightly elevated in some of the side tributaries due to the steep slopes required to connect with the main channel. All but one of the south side tributaries are conveyed under the Lionkol Road by a culvert with a rock structure. Higher shear stresses are also present in the main channel under the flood-prone condition due to the large contributing upstream area. These shear stresses were allowed to exceed the design criteria because the channel gradient was flatter than the native condition. In addition, the impoundment serves as a final containment structure should excessive erosion occur.

In the previous phases, shear stresses were maintained within the design limits by utilizing small basins and traditional structures, or by accepting high shears as representative of the native environment. For this phase, regional regression equations were used to estimate the contributing area runoff. The NR method of runoff estimation using the Rational Method is conservative and based on theoretical values. The Miller (2003) method uses empirical data (i.e., streamflow gauges) to extrapolate flows within a given region. The values from Miller (2003) were entered into NR in the Watershed tab of the Channel Settings dialogue box in the Manual Qpk for additional area, shown in Fig. 9. For small drainages, there was little difference in the flows from the NR Rational Method and the regional regression equations. Therefore, Miller (2003) only was used to estimate storm flows for large, additional areas that flowed onto the project. Application of region regression equations resulted in more realistic flow estimates due to the natural routing 
of flows, and in shear stresses closer to the design criteria

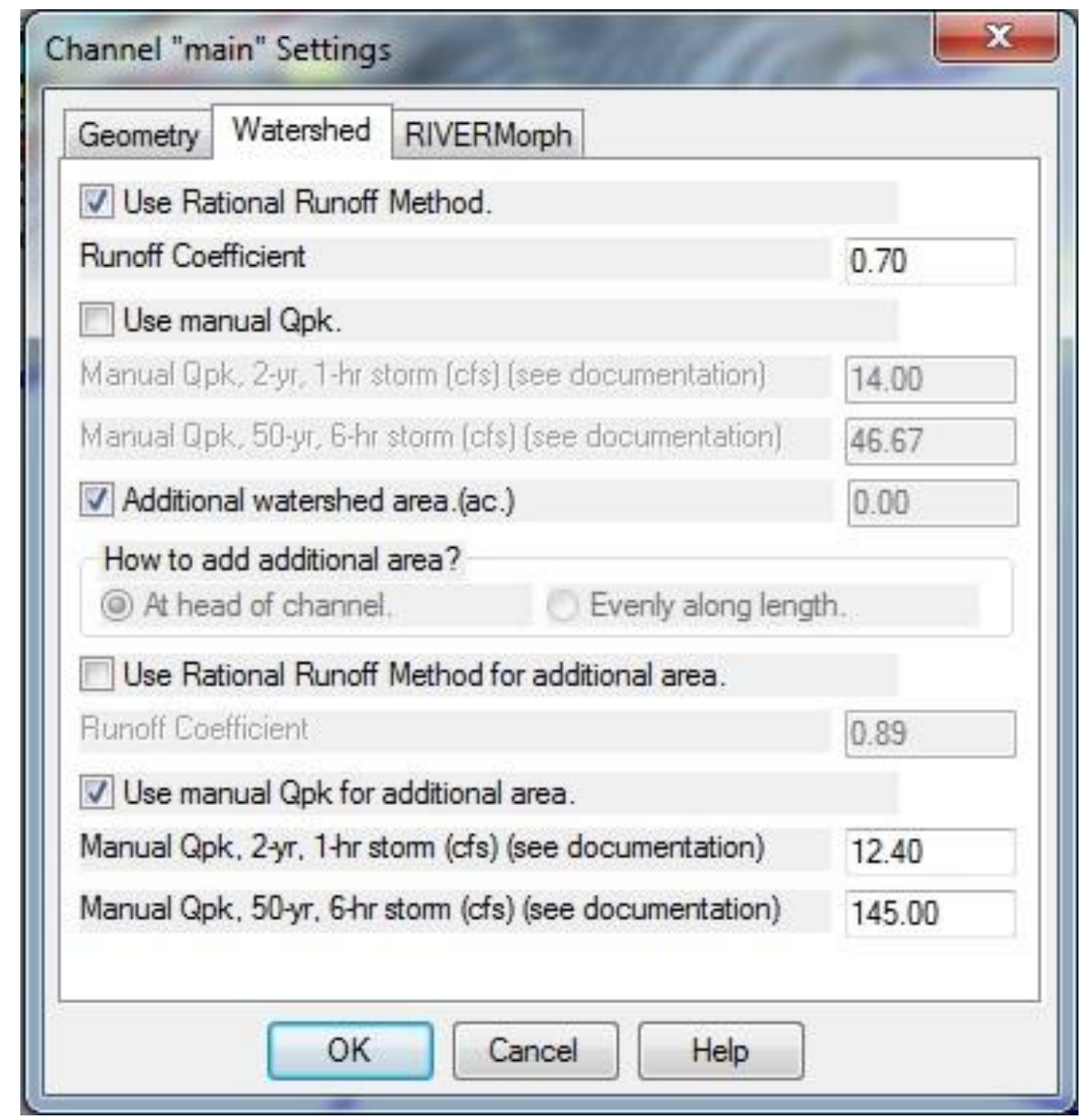

Figure 9. Natural Regrade ${ }^{\mathrm{TM}}$ Channel Settings dialogue box, Watershed tab. Variables are entered in this tab for the runoff modeling.

\section{Lionkol West Drainage}

The Lionkol West Drainage Project is located around the Bureau of Land Management (BLM) Wild Horse Holding Facility, just downstream of the Lionkol drainage project, as shown in Fig. 10. The Lionkol West drainage had been straightened to make room for the mine haul road and railroad grades. The BLM Wild Horse Holding Facility also restricted the channel by realigning the channel around the facility and eliminating channel meanders. As a result, the channel gradient was steepened, resulting in incision and increased erosion. Once a channel incises, flows no longer have access to the floodplain and concentrate in the incised channel, creating more erosion during each storm event. The reclamation goal for this project was to stabilize the channel and re-establish the floodplain. Unlike the previous phase, raising the channel 
bottom was not possible due to three existing culvert crossings within the project limits. The reclaimed channel gradient had to match these fixed points and provide a stable channel. The project was divided into three design segments to address each channel reach constrained by the culverts: The Upper Reach, the Central Reach, and the Lower Reach. Due to the incised and constrained nature of the channel, achieving earthworks balance was not possible, and the project generated excess material.

Another design challenge was the management of runoff from the BLM Wild Horse Holding Facility. A retention system was necessary to collect nutrient dense flows through the facility. The Lionkol drainage is a tributary of Kilpecker Creek, which is listed as an impaired stream due to elevated levels of fecal coliform. The Lionkol drainage ran through the middle of the corrals, and the constrained valley made it difficult to site a retention pond. Two smaller retention ponds were proposed and integrated into the overall design to assist the BLM in managing their storm water runoff.

BLM approached the Wyoming AML regarding the bidding and construction of the BLM ponds and other facilities related to the Wild Horse Holding Facility. The Wyoming AML agreed, and project bidding and construction were combined in the fall of 2013. Combining the projects reduced costs to both the BLM and the Wyoming AML through economy of scale. In addition, the excess material from the Wyoming AML project was used to construct one of the retention structures and to provide a material stockpile for use in the BLM facility.

On the project's west end, the stormwater flows from the BLM office building parking lot were incising and eroding material into the Lionkol drainage. The design incorporated a riprap-lined "A" channel to convey the flows into the main Lionkol drainage and prevent further erosion. Near the downstream end, a pipeline right-of-way and cultural area restricted the project limits, as shown in Fig. 11. The channel design had to be manipulated in the area to avoid interference with the pipeline and cultural area. 
Journal American Society of Mining and Reclamation, 2017 Vol.6, No.2

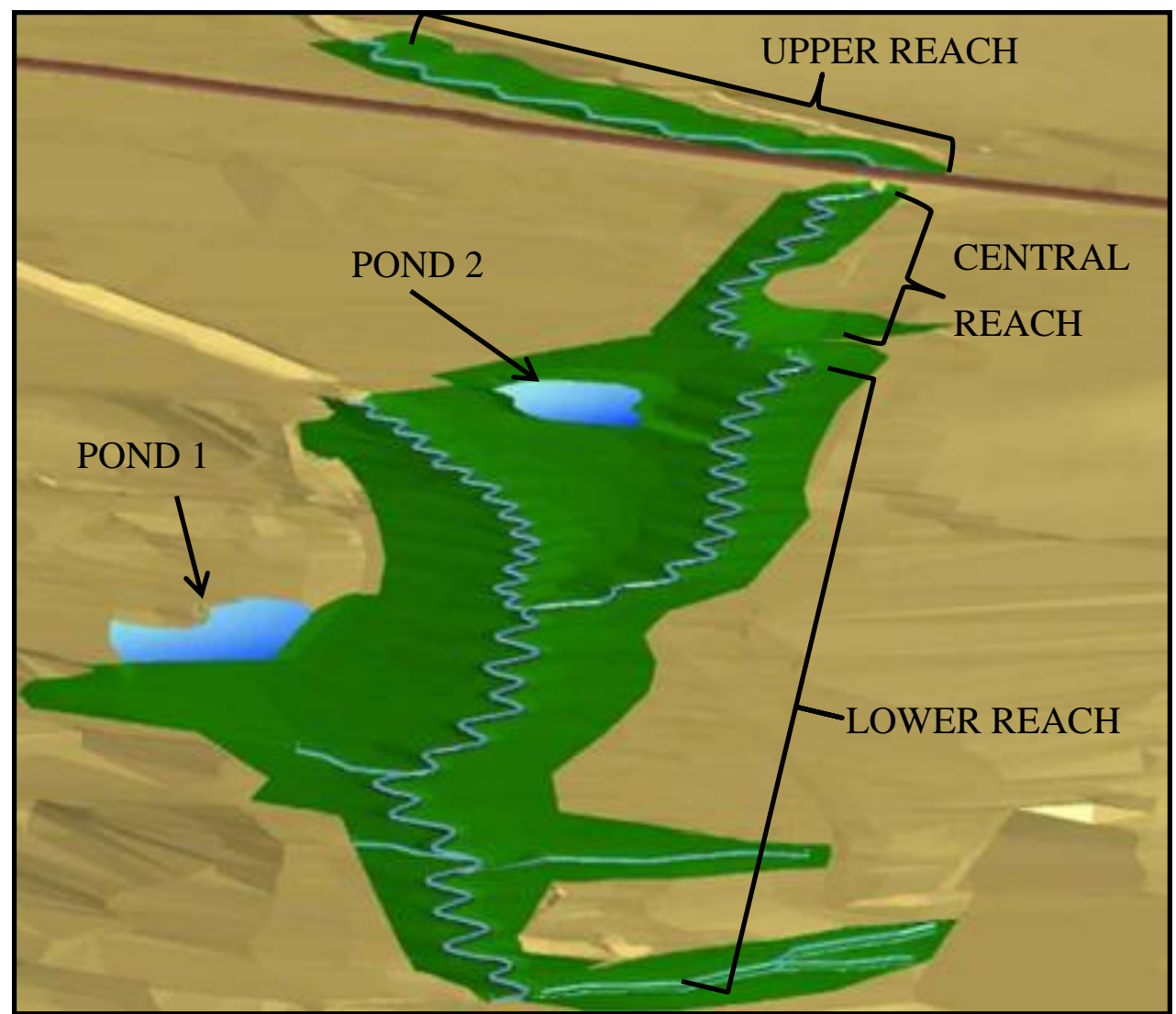

Figure 10. Lionkol West drainage design with 3D rendering. The site was constrained by culverts, so the design was split into three reaches.

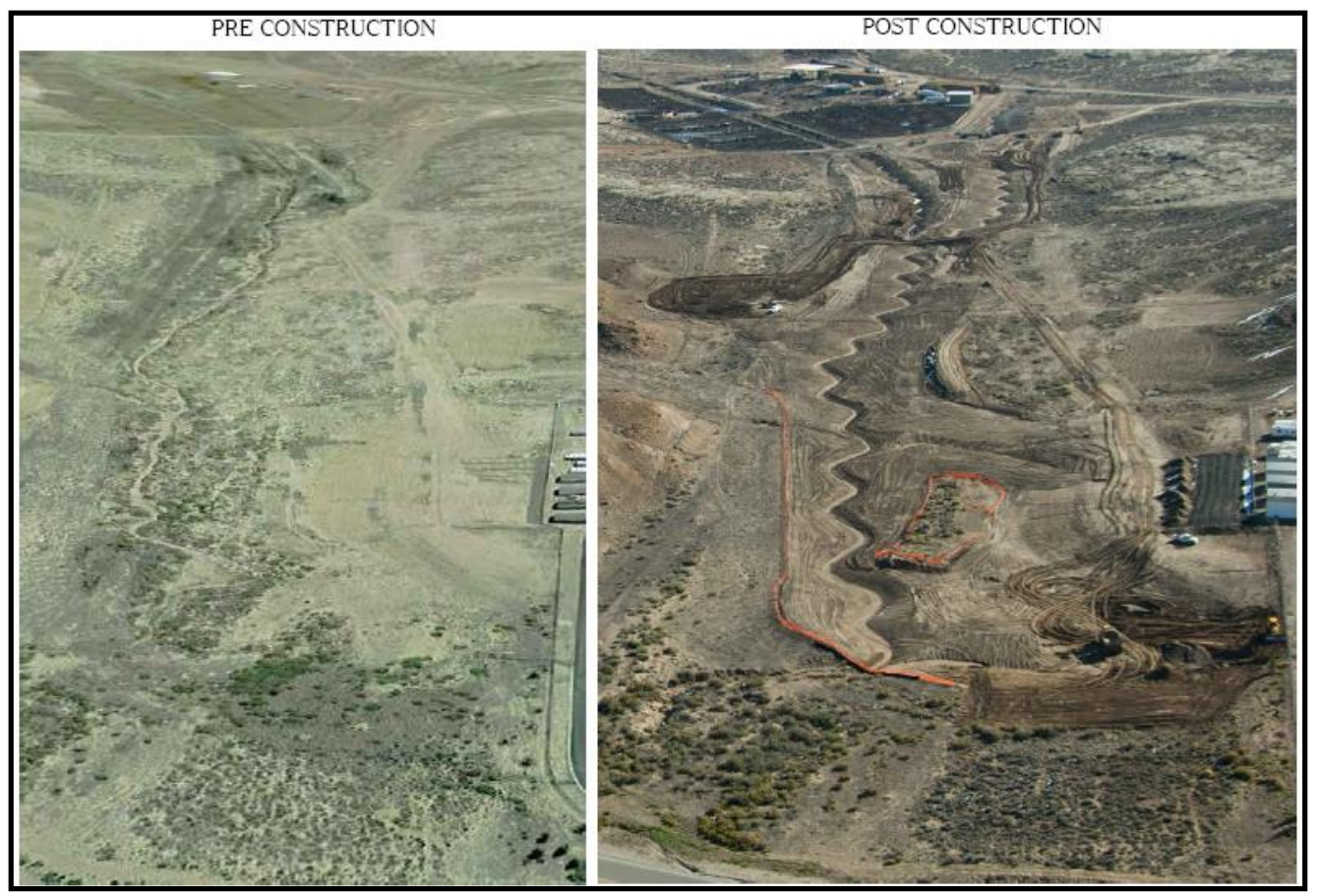

Figure 11. Lionkol West drainage before and during construction. Cultural features and a pipeline were fenced with orange safety fence. 
The design consisted of three projects with a total of 0.7 miles of valley length and $60 \mathrm{ft}$ of vertical relief. Again, Miller (2003) was used to estimate runoff from the upstream areas, which estimates lower flows than those estimated by NR. The shear stresses calculated using the flows estimated using Miller (2003) met the shear stress stability criteria. During construction, three large storm events occurred resulting in channel flow. The situation provided a unique opportunity to see how the partially completed channel performed under large flow events. Areas damaged by the flows were observed, providing insight into how best to repair the channel and reduce future damage. Repairs were monitored for performance and changes to the repair strategy were made as necessary during the subsequent storm events. The primary method of repair was to collapse the cut-banks and use the material to raise and widen the channel bed.

\section{$\underline{\text { Performance Evaluations }}$}

An analysis of the constructed areas was performed as noted, in addition to the many observations that were not formally documented. What follows is an anecdotal account of channel stability in the evolution of geomorphic channel design in the Lionkol drainage.

\section{$\underline{\text { Reliance No. } 11 \text { North and South Pits }}$}

A field inspection of the channels on the Reliance No. 11 North and South Pits was completed in late July and early August 2013. The site was re-vegetated in fall 2009, providing four growing seasons for regrowth to occur. Site re-vegetation was variable, ranging from no vegetation present to small islands of sparse range grass and forbs. The site exists in an arid area, with little to no cover-soil material available and $\mathrm{pH}$ and salinity issues in the spoils, contributing to a difficult area for re-establishment of vegetation. As a result, little attenuation of runoff is occurring due to vegetation. Notwithstanding the relatively poor vegetative cover, the majority of the channels were functioning properly. The following observations were made of the geomorphic channels:

- All of the geomorphic channels were found to have stable uplands.

- Meandering channels exhibited repetitive phases of cutting and deposition $50 \mathrm{ft}$ long by 6 in. deep, consistent with natural channel behavior in the area.

- Pilot channels 8 to 10 in. deep were created by concentrated flows, typically related to adjustment of the channel bed to inconsistencies in the channel grading and/or downstream of confluences with higher combined flow.

- Moderate armoring and stabilization of the pilot channels with 4-8 in. diameter rock occurred where allowed by spoil materials. 
- Vegetation was successfully established in the majority of the armored channels.

- Minimal amounts of coal or other undesirable materials were being exposed and redistributed.

- The performance of the geomorphic channels in Reliance No.11 North is consistent with natural channel behavior shown in Fig. 12, which is the goal of the project.

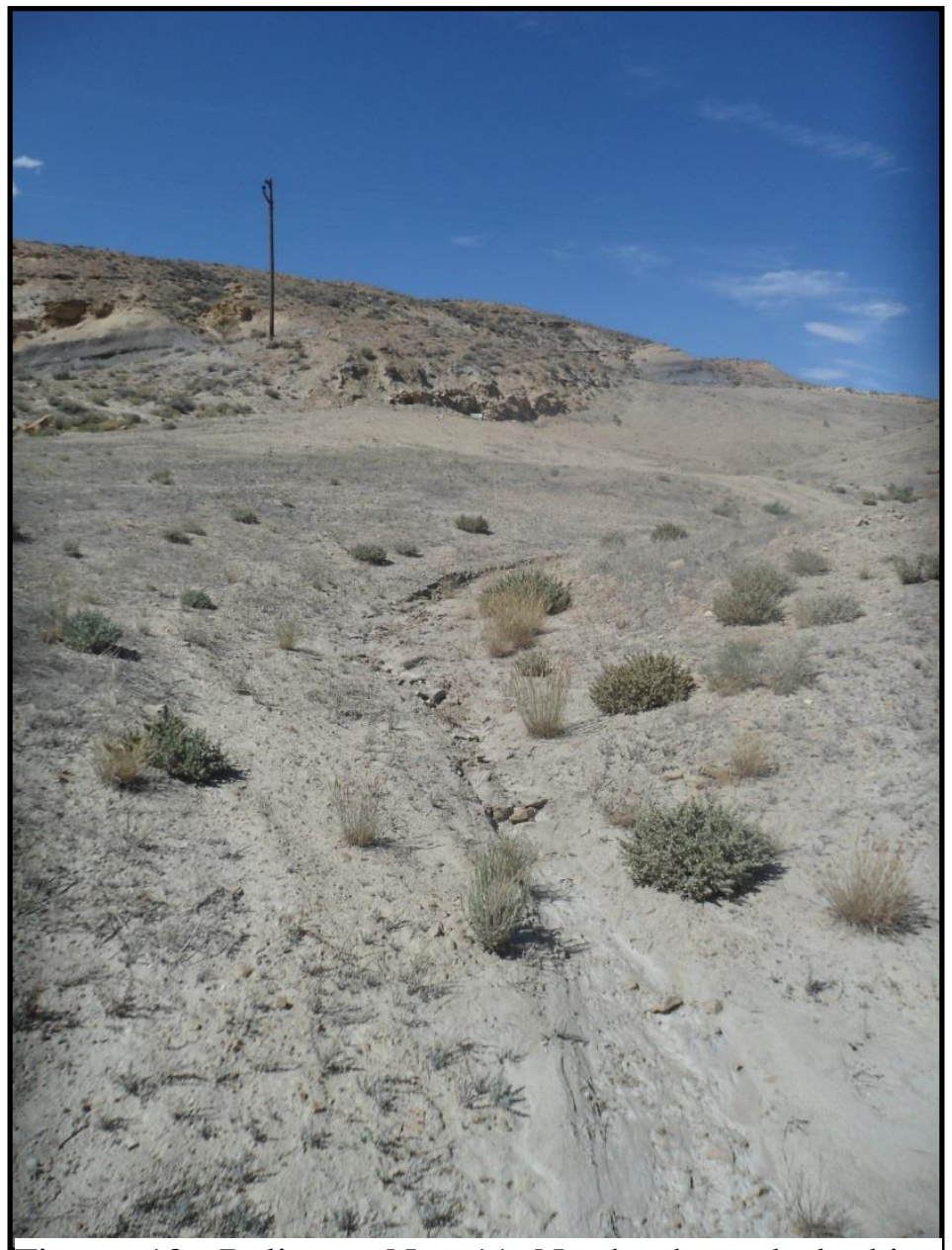

Figure 12. Reliance No. 11 North channel, looking upstream at a pilot channel forming in the channel bed. The channel is stable.

A single failure, requiring repair, occurred within the traditional channels located west of the North Main Pond shown in Fig. 13. Steep channel gradient (>10\%) and the 22-ac contributing drainage basin caused failure of the channel, resulting in a $50-\mathrm{ft}$ long by 2 to $2.5-\mathrm{ft}$ deep pilot channel. The failure formed upstream of the confluence between the traditional main channel and its tributary, exposing coal and shale. Erosion diminished and ended in an area of deposition $30 \mathrm{ft}$ downstream of the confluence. 
Repairs were made to the traditional channels in the fall of 2013. Wheel rolling the pilot channel with a scraper was performed to restore a widened channel flow-line and provide compaction. In general, the geomorphic channel provided superior performance compared to the traditional channels in Reliance No. 11 North Basins.

An inspection in the fall of 2016 found the traditional channel in the Reliance No. 11 North Pit had incised again. The traditional channel is mostly straight and needs channel bends to reduce energy. Future repairs to this reach will include redesign with a geomorphic channel configuration.

Geomorphic channels within the South Spoils area were found to have been damaged by vehicles, as they had been used as roadways following reclamation. However, the channels were still performing well. Natural bedding of bedrock was observed to be anchoring the channel flowlines and no unnatural level of erosion was observed to be occurring at the time of inspection, despite the post-reclamation damage to the channels by off-road vehicles. The most active pilot channel formation in the area occurred within a 20-ft channel segment within the South Main geomorphic channel. Following multiple unseasonably heavy rain events during fall 2013, the site was revisited and the original 18-in. deep pilot channel had repaired itself. However, a sub-ridge failure upstream of the same confluence had developed and was cutting 10 to $18 \mathrm{in}$. deep along a 150-ft long channel reach. The channel segment was repaired in fall 2013 by widening the flowline and reinforcing the channel banks. This repair is expected to decrease the flow depth within the channel and reduce erosion to an acceptable level. No other repairs were deemed necessary.

The traditionally-designed channels and slope draining into South Pond 2 did not perform as well as the slopes containing geomorphic design elements. The traditional channels were moderately vegetated with brush and weakly incised with pilot channels less than 6 in. deep. However, weak to moderate rilling was observed across the surface of the slope indicating some runoff flowing outside the designed channels. Poor material quality, high gradient (>10\%), and low channel density are the primary factors for the water flow outside of the designed channels. Rilling was overprinted by vegetation and had no fresh sediment movement. As such, the revegetation appears sufficient to retain the stability of the slope and a more natural drainage pattern is developing. No repairs were recommended. 


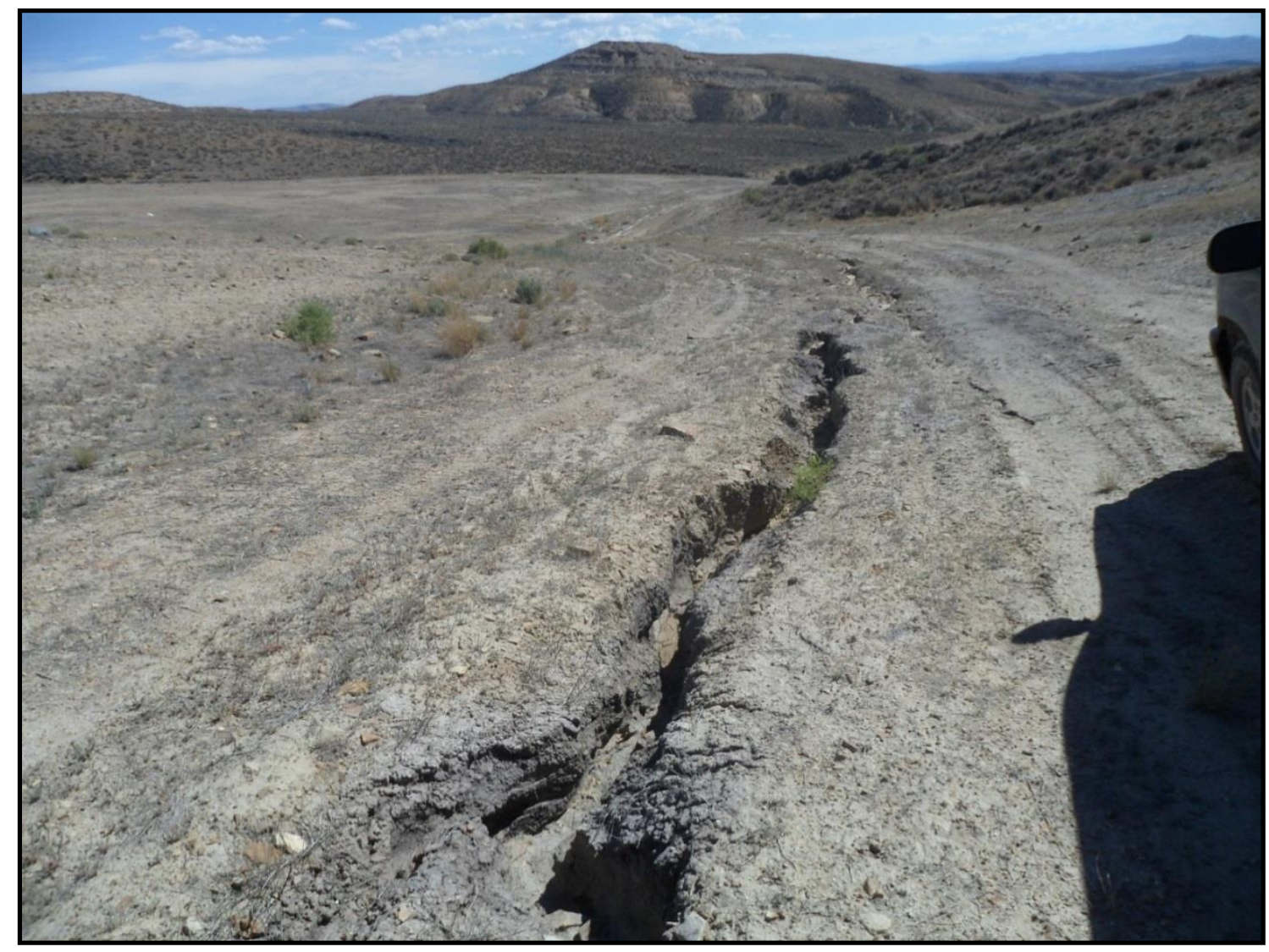

Figure 13. Traditional channel failure in the Reliance No. 11 North Pit, looking downstream. Steep channel gradient was the cause of the failure.

An inspection in fall 2016 noted that vegetation growth had improved significantly, and that the geomorphic channels were performing well. Some of the channels had minor erosion, but were beginning to armor and appeared to be in dynamic equilibrium.

\section{$\underline{\text { Reliance No. } 3}$}

A field inspection of the channels in Reliance No. 3 was completed in late summer 2013. The site was re-vegetated in fall 2009. General performance of the geomorphic channels was in line with the expected behaviors of naturally establishing channels and is similar to that of both Reliance No. 11 sites. Vegetation was observed to be limited to small communities located in depressions, sheltered areas, and along channel flow-lines and banks, areas that collect water from runoff and snowmelt.

The largest failure requiring repair was along the main channel of the North Spoils, shown in Fig. 14. The channel was incised between 6 and 18 in. along its length, and had several meander bends completely shortcut by pilot channel formation. Following unusually high precipitation in 
fall 2013, some of the channels cutting through the meander bends had self- repaired. However, since the channel was designed with high shear stresses and the erosion in the remainder of the channel had not self-corrected, the entire channel needed to be widened to prevent continued flow concentration in the pilot channel. The channel was repaired in fall 2013 to widen and reinforce the channel.

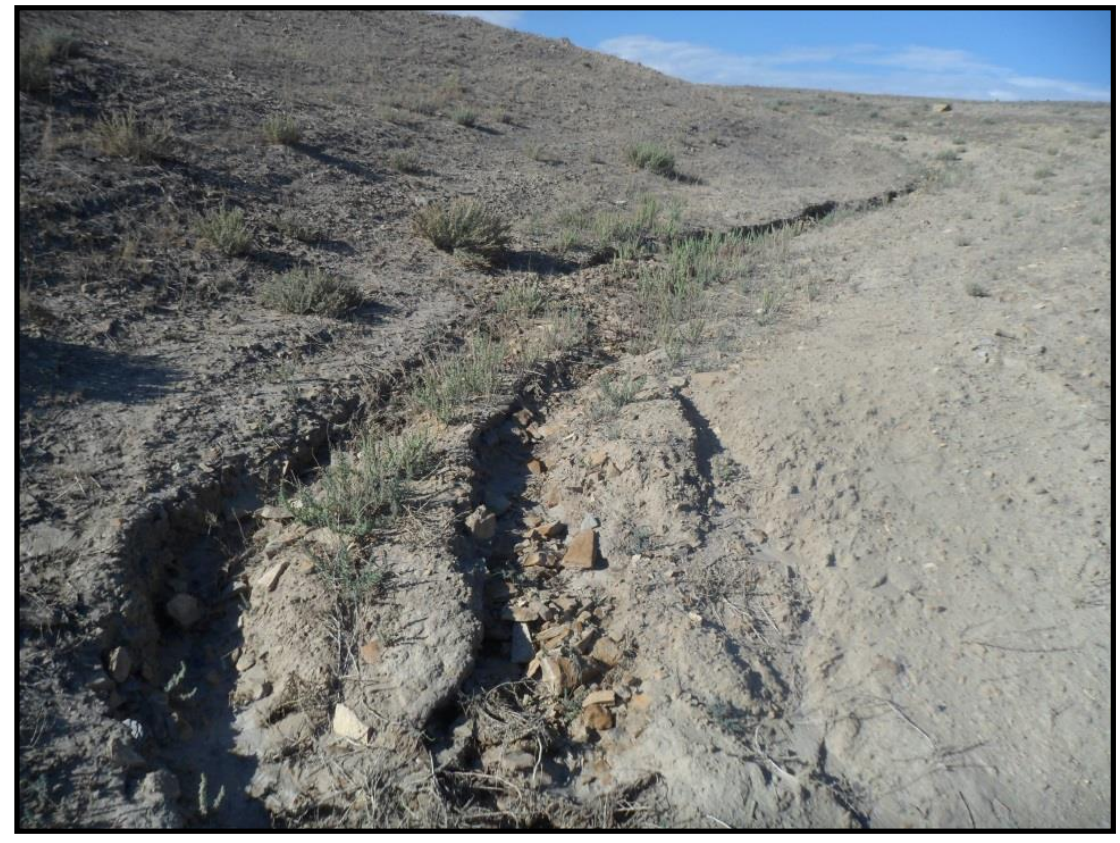

Figure 14. Reliance No. 3 North Spoils main channel failure, cutting through the point bar. The channel was repaired and widened.

Despite high designed shear stresses within the Reliance No. 3 Main Valley, the channels were found to be performing well and did not require repair. The Reliance No. 3 Valley 2 basin channels behaved equally well. Although a handful of channel reaches exhibited pilot channel formation of up to $18 \mathrm{in}$. deep, they were typically less than $20 \mathrm{ft}$ long and did not warrant repair.

The outlet of the Main Valley and Valley 2 basins also had high design shear stresses. However, erosion was confined between the riprap structures. Water exiting the upstream riprap structure was sediment starved or lacking suspended load and bed load. Consequently, the sediment "hungry" water was cutting a 12-in. pilot channel into the downstream channel, and then re-depositing the sediment down-gradient in the downstream riprap structure. As the voids between rocks in the riprap structures are filled with sediment, the erosion should stabilize. An inspection in fall 2016 found this to be true, as most of the reach had stabilized. Some minor 
erosion of the main meander channel was observed, contrasted by the continued stability of the upland tributary channels.

Other, smaller failures within the northern area of the Reliance No. 3 site were largely due to the construction of short channel lengths above the natural surface grade. The North Pit main channel was found to have a 15 -ft channel reach incised with a $2.5-\mathrm{ft}$ deep pilot channel. Due to the small size and cause of the failure, the channel is expected to be self-correcting and was not repaired.

\section{$\underline{\text { Lionkol Main Pits }}$}

A field inspection of the channels in the Lionkol Pits was completed in August 2013. The site was re-vegetated in fall 2009, but compared to the other reclaimed areas, was poorly re-vegetated. Runoff volumes are expected to continue to be high with little attenuation due to poor vegetation.

Channel performance in the Lionkol Main Pit area was mixed. Stable channels were observed even at higher gradients due to the small drainage areas. The relatively low shear stresses modeled by NR supports this conclusion. Poor performance of a few of the channels within the largest basins in the Main Pit area was noted. Main drainages required repair. Smaller basins were found to have performed well and behaved similarly to geomorphic channels in Reliance No.11 North.

Failures within the main channels were less than 100-ft long and between 12 and 18 in. deep, requiring simple reinforcement repairs. The North Main channel had become completely incised exposing bedrock between 18 and 36 in. below the design grade by fall 2013, as shown in Fig. 15. Although the channel was hard-pointing on bedrock, and would eventually have corrected itself, the process would have required many years and would have resulted in unacceptable amounts of sediment being transported downstream. Therefore, the channel was widened, maintaining the incised grade for the entirety of its length. The increase in cross sectional flow area is expected to reduce the flow energy within the channel and limit unacceptable levels of continued erosion. In addition, the ditch on the south side of the road into which the channel drains, was reinforced.

To address the poor vegetation and steep slopes in the Lionkol North Main drainage, multiple pockets or depressions were cut in rilled areas. The depressions were 8-ft wide by approximately 20-ft long and 1- to 2-ft deep. The depressions trapped water, reducing further erosion, and provided a water source for vegetation growth. Inspections in 2015 and 2016 noted improved vegetation growth in the depression areas. However, the eventual siltation of the depressions 
caused little water to be retained. Additional depressions were constructed in between the existing depressions in fall 2015. In the Lionkol Lower Spoils and Lower Pit, areas with poor vegetation growth were amended with manure and reseeded in 2013. An inspection in fall 2016 noted improved vegetation growth with minimal erosion. Minor channel work was completed at the outlet to the Lionkol Main channel in connection with work completed in the Lionkol Main drainage in 2016.

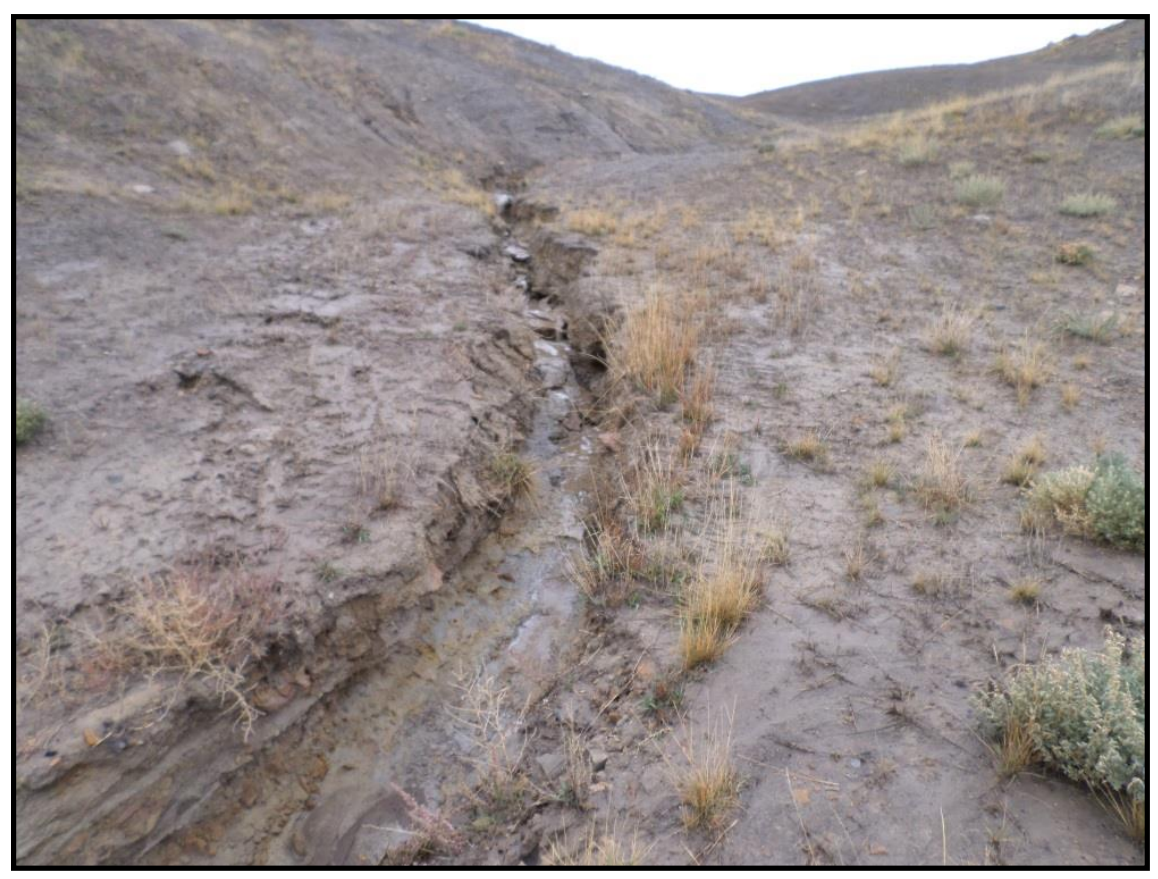

Figure 15. Lionkol North Main channel failure, incised to bedrock. The channel was repaired by widening the bed and sloping the banks.

\section{Lionkol Main Drainage}

The Lionkol Main drainage was inspected in fall 2013, and again in 2015 and 2016. The main drainage sustained limited damage during heavy storm flows in fall 2013. Repairs were focused on the rock structures downstream of the culverts conveying flow under Lionkol road. The main channel performed well, with limited cutting of the channel bed, and small $(<1 \mathrm{ft})$ cut banks.

Large flows in summer 2015 resulted in channel cutting and cut banks forming. Repairs were completed in fall 2015 and consisted of sloping the cut banks to fill and widen the channel bed. These were unusually heavy storm events for the region, and reshaping the channel was deemed sufficient to stabilize the area. 
Storm flows in the Lionkol drainage in the spring and summer of 2016 surpassed those of the previous years. The Lionkol Stock Reservoir, designed to contain the 100-year storm volume, filled, and the spillway conveyed excess flows. The main channel sustained damage that required repairs, as shown in Fig. 16. Repairs were performed in fall 2016 and included a re-design of the channel where the Upper and Lower drainages meet (Fig. 7). This is an area where two design

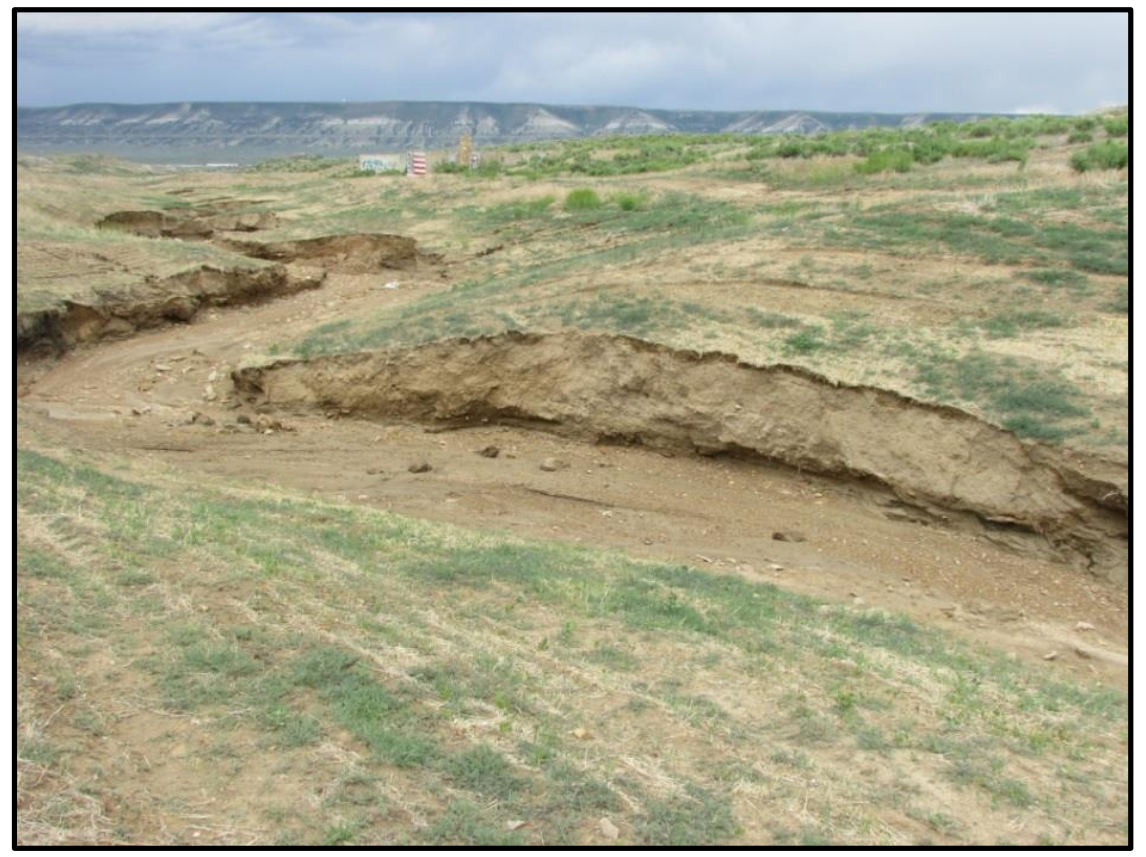

Figure 16. Channel bank cutting in 2016 at the confluence of the Lionkol Upper and Lower drainage. Repairs were made through a re-design of this section.

channels converged to avoid historic structures. The discontinuity in the channel slopes at this confluence created channel instability. The re-design smoothed the slope transition over approximately $300 \mathrm{ft}$ of channel. Instead of filling the channel by sloping the banks as was completed previously, the channel bed was left at its elevation and width. The channel banks were sloped back, and the excess material was used to reinforce the toes of the meander bends as shown in Fig. 17. The channel width increased from the NR design width of approximately $2.5 \mathrm{ft}$ to the existing width of 6 to $8 \mathrm{ft}$. Approximately half of the channel length required repairs. 


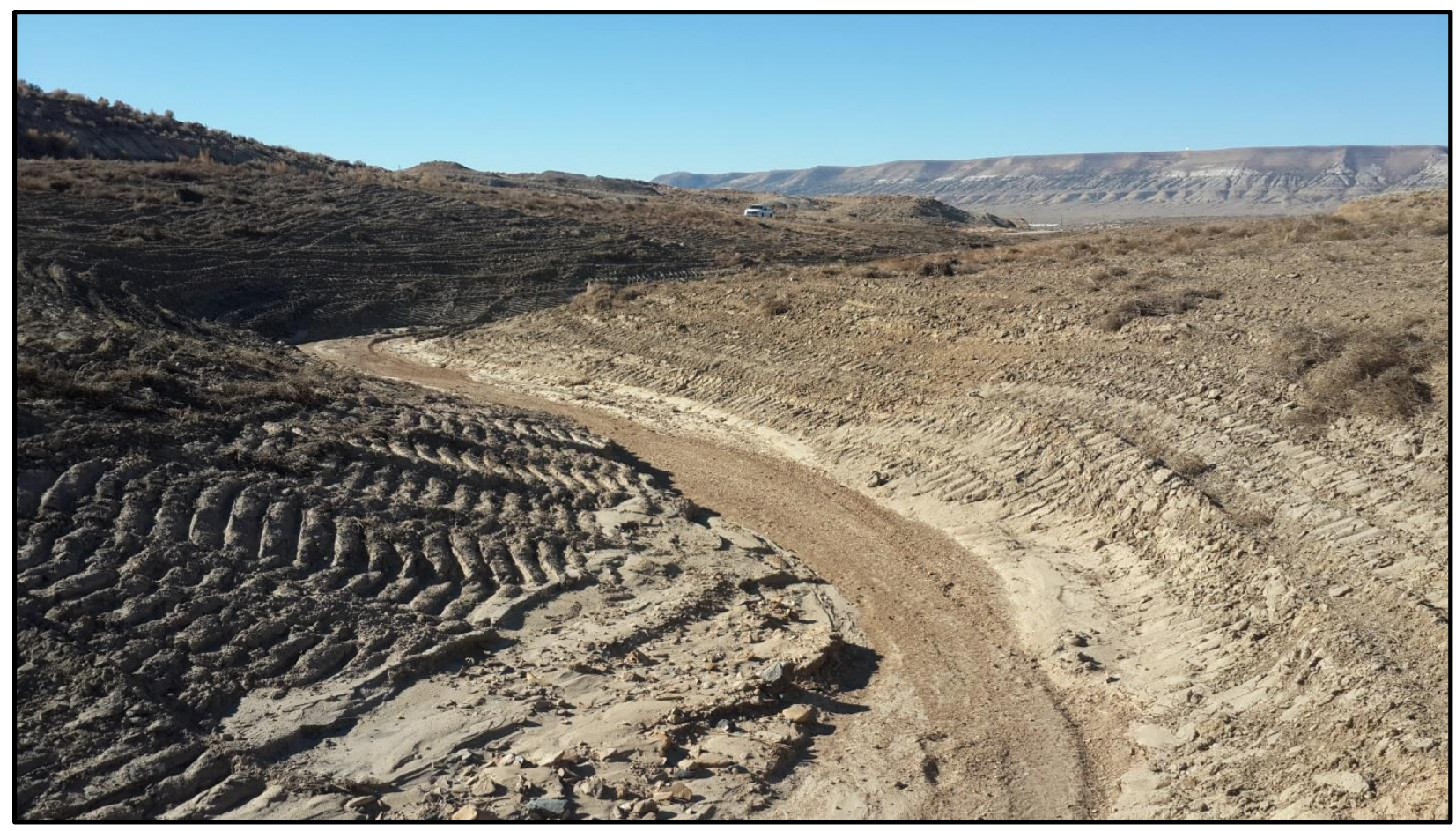

Figure 17. The regraded main channel of the Lionkol drainage after repairs in fall 2016. A storm event tested the channel shortly after the repairs were made.

Due to the series of years with above-average precipitation, a retention structure was added to restrict the flows in the main channel. This was accomplished by building an embankment over a road crossing upstream of the project and restricting the flow to a single 48-in culvert, roughly equivalent to the 50-year runoff. In addition, four rock structures along the Lionkol drainage required minor repairs.

Storm flows occurred shortly after construction in fall 2016. Although not as large as the previous stormflows, flow depths were approximately 1 to $2 \mathrm{ft}$ deep. The channel performed as designed with no significant erosion.

\section{Lionkol West}

During construction, Lionkol West experienced three separate heavy storm flows, with a return interval of between a 10-year and 25-year storm. The flow during these events was up to $3 \mathrm{ft}$ deep in the main channel and cut into the banks in one location up to $2 \mathrm{ft}$ deep, as shown in Fig. 18. Erosion damage from the storm required the contractor to refinish sections of the channel. The storms provided a real-world test of the various channels while an engineer was onsite to observe. Because the multiple storm events were of similar magnitudes ( 0.23 to 0.5 in. per 24 hours), it was 
possible to see how the repairs performed and make changes to the repair strategy where necessary.

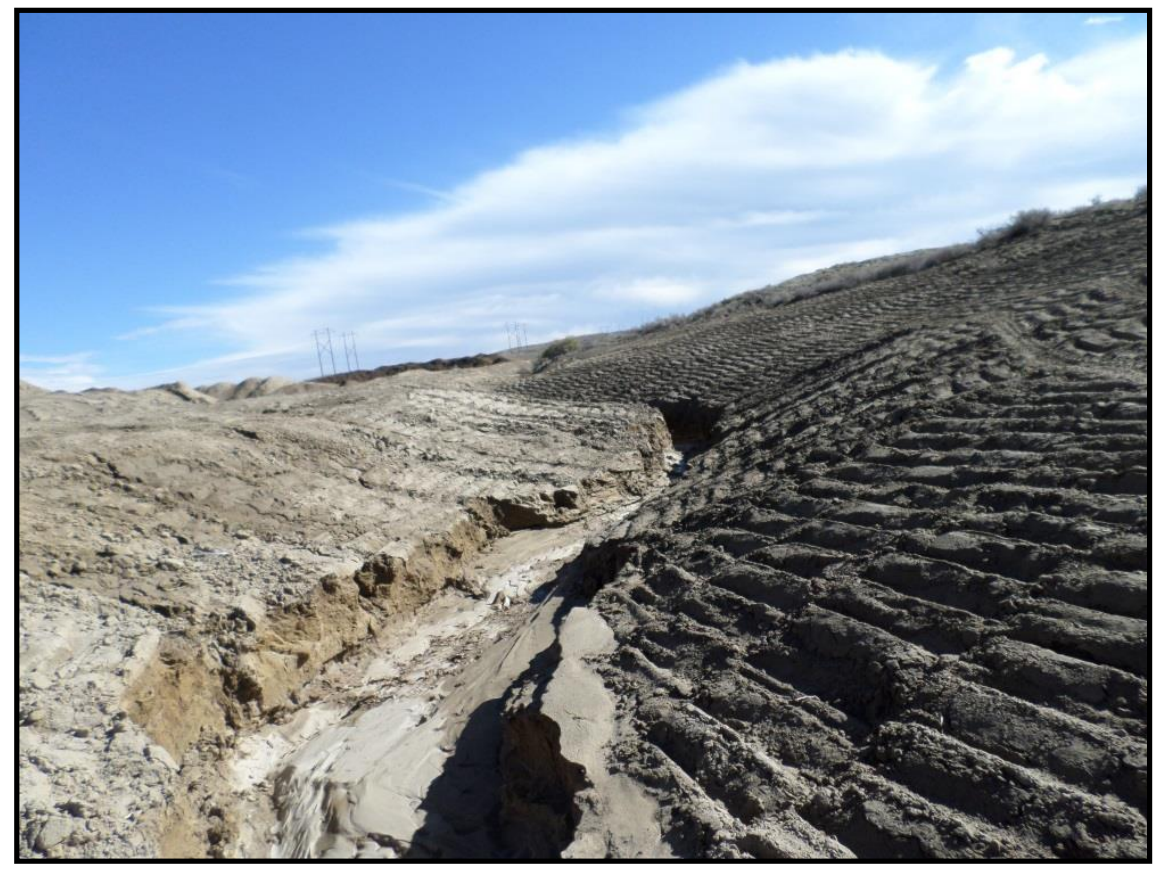

Figure 18. Lionkol West, Upper Reach. Channel erosion from storm events during construction.

Smaller repairs in the channels consisted primarily of collapsing cut banks and widening the channel bottom. A large head-cut in the upper portion of the main channel was repaired by replacing the eroded material to maintain a stable grade. Below the box culvert, a concrete apron was constructed to protect the channel, and a rock structure was installed at the end of the apron to dissipate the energy from the flow.

Shortly after the last storm event in September 2013, high-water marks were identified and marked for survey just upstream of the box culvert over Lionkol road. A channel survey was completed to estimate the peak discharge and evaluate the frequency of the event. The data were analyzed in AutoCAD. Data were entered in the U.S. Army Corps of Engineers, Hydraulic Engineering Center River Analysis System (HEC-RAS) software to estimate the flow. Roughness factors were estimated from soil type, vegetation cover, and channel transitions observed in the field. The surface water profiles calculated in HEC-RAS were checked against the observed highwater marks. The surface water profiles matched the general trend of the observed high-water marks. A rating curve was plotted in HEC-RAS for cross-section 4 and the flow at the high-water mark was estimated to be 94 cubic feet per second (cfs). Return interval runoff was evaluated using the regional regression equation developed by the U.S. Geological Survey (Miller, 2003). 
Table 1 shows the return-interval runoff estimates for the channel at the survey location. From Miller (2003), the storm event of $94 \mathrm{cfs}$ is between the 10-year and 25-year storm. In general, the meander channels performed well considering they were newly constructed and virtually void of vegetation.

Channel inspections were conducted in fall 2015 and 2016. Minor channel repairs were made in fall 2015, mostly to repair rock structures. In 2016, repairs were made to the Central Reach next to the BLM Horse Corrals. The same approach was used to leave the channel bed at its current elevation and width, and slope the banks back. This provided a wider channel than the NR-based design and helped reduce flow depth and subsequent shear forces. Figure 19 shows the channel during a storm event, after repairs were made.

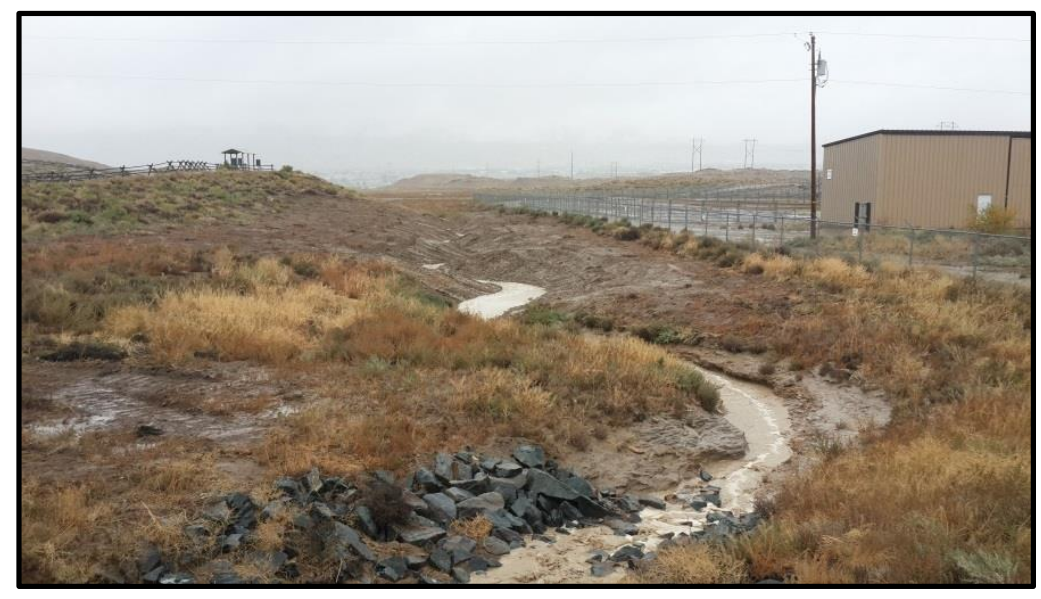

Figure 19. Lionkol West, Central Reach. Stormflows were observed after repairs were made in 2016.

Table 1. Lionkol West return interval runoff using Miller (2003), region 6.

\begin{tabular}{|c|c|c|c|}
\hline Drainage area (ac) & Qp & cfs & ac-ft \\
\hline $835 \quad$ (ac) & Q2 & 14 & 1.3 \\
\hline $1.30 \quad\left(\mathrm{mi}^{2}\right)$ & Q5 & 40 & 3.3 \\
\hline & Q10 & 67 & 5.3 \\
\hline & Q25 & 115 & 8.5 \\
\hline & Q50 & 162 & 11.4 \\
\hline & Q100 & 217 & 14.8 \\
\hline
\end{tabular}

A rock structure was added at the confluence of main channels in the Lower Reach (see Fig. 10) to control erosion of the channel banks in this area. Minor repairs were made to some of the 
remaining rock structures. In the Lower Reach, minor repairs were made to the channel banks where flows had cut the banks. Two tributary channels were added to direct flow into the main channel, and water bars were used to direct flow into the tributary channels.

\section{$\underline{\text { Summary and Conclusions }}$}

The Lionkol Project fully implemented new methods in geomorphic mine land reclamation to achieve a sustainable reclaimed landscape that blends with native topography and provides for long-term stability. The project was funded primarily through the Office of Surface Mining with additional funding provided by BLM. The project addressed hazards and environmental degradation related to historic surface and underground coal mining while preserving the historic aesthetic. Additionally, both the City of Rocks Springs and the BLM benefitted from this project.

Overall, the project reclaimed 320 ac of disturbed mine lands including four open pit complexes, associated mine spoils, and numerous underground mine portals, shafts, and subsidence features. In addition, over 5 miles of degraded mainstream drainages were reclaimed. The Lionkol Project was supportive of efforts by the City of Rock Springs to attenuate peak runoff events critical to reducing floodplain designations, and was integrated with BLM efforts at its Wild Horse Holding Facility to control surface runoff and be compliant with Department of Environmental Quality regulations.

The four reclamation projects completed using the Natural Regrade ${ }^{\mathrm{TM}}(\mathrm{NR})$ software and geomorphic design concepts were reviewed in the Lionkol drainage to assess channel stability and overall project success. The time since completion of the projects ranges from 3-8 years and provides an adequate sampling of sites to evaluate project success. The timeline also provides for evaluation of the design concepts, NR design criteria, and review of the input parameters.

The geomorphic reclamation methods at each successive site evolved to reflect lessons learned from the previous phases. Whereas the first phases relied heavily on a mix of traditional and geomorphic reclamation techniques, the subsequent phases came to incorporate more NR designed structures as well as more realistic native channel and surface water runoff characteristics. Although no extreme failure of any channel was observed, the overall behavior of the geomorphic channels is judged to have been superior to the traditionally designed channels, both in function and aesthetics. 
In total, 14 out of 85 channels experienced damage, thus requiring repairs. Of these, three were failures of the entire channel. The remaining areas required repairs to limited reaches within the channel. Significantly, all of the failures were related to over-steepened "A" channels in uplands areas with contributing basin areas. The majority of these failures were located on the Lionkol Main Pit, Reliance North Pit, and Lionkol Drainage. For the Lionkol Main Pit and Reliance North Pit failures, the failed channels are located on ridges with steep natural gradients. For the Lionkol Drainage, all of the failures were related to over-steepened channels downstream of culverts under Lionkol Road. These failures cannot be attributed to geomorphic design approach, but to the modification of gradient required by the road and culverts, and inadequate engineering controls in the initial design, which were subsequently repaired. None of the main meander channels, including those with large contributing basin areas, experienced failure. Future design emphasis will be placed on managing contributing flows in steep uplands basins.

Variability in the performance of the channels within the Lionkol Project speaks to the variable components impacting the runoff of each basin. Any of the components of failure (e.g., steep slopes, high shear stresses, large drainage area, high runoff, poor soils, poor vegetation) taken singularly is not likely to result in failure. However, combinations of these factors have been observed to cause unacceptable erosion. Understanding of the magnitude of each component's role in failure can assist in improving future geomorphic designs using NR. Future investigation would benefit this understanding.

In conclusion, the performance of the geomorphic features designed with NR in comparison to the traditionally designed elements in the Lionkol project areas supports the continued use of geomorphically designed elements in future reclamation projects. The authors recommend that such reclamation projects include NR design methods that integrate changes in paradigm affecting design parameters, site characterization, monitoring, control and retention structures, and adjustments to NR design output. Following is a discussion of each.

\section{Design Recommendations}

Selection of design events should be based on the local setting and purpose of the reclamation projects. If there is potential for downstream flood damage, greater levels of control and/or more conservative design events may be considered. The Lionkol Project is located in an unpopulated area, however the BLM Wild Horse Holding Facility, a state highway, and the City of Rock 
Springs are located downstream of the site. Design parameters for the Lionkol Project included:

- Bank-full conditions; 2-year, 1-hour precipitation event.

- Flood-prone conditions; 50-year, 6-hour precipitation event.

- Storm water retention and/or grade control structures and impoundments; 100-year, 24-hour precipitation event for stability and back-to-back events for storage.

- Regression models were used to determine contributing runoff during later phases (Miller, 2003).

Site Characterization

Accurate surveys of existing channel profiles and cross sections, and basin characteristics are needed within the design reach and surrounding native channels including:

- Drainage density,

- "A" channel or tributary channel reach lengths,

- Bank-full and flood-prone channel dimensions (e.g., width, depth, meander length),

- Vegetation types and locations,

- Erosional and depositional modes (e.g., rilling, piloting, armoring, braiding, point barring), including sediment load and grain size distribution

- Sinuosity of native channels,

- Channel gradients,

- Channel capacities, and

- Sufficient topographic mapping to define contributing drainage areas and local drainage divides.

\section{$\underline{\text { Adjustments to Natural Regrade }}{ }^{\mathrm{TM}}$ Design Output}

Natural Regrade ${ }^{\mathrm{TM}}$ software optimizes geomorphic stability, but does not always produce constructible earthwork designs. The algorithm functions best in conditions with limited vertical relief. Open pit highwalls and large mine waste stockpiles often have extreme vertical relief over relatively short distances, which present a challenge to the software. This requires multiple design iterations wherein the NR output is adjusted in AutoCAD. Typical requirements for steep terrain projects include:

- Prior to application of the NR software, define limits and main design features of the project 
including the location and alignment of major drainages and basins.

- After developing a preliminary or conceptual design surface, apply NR to that surface.

- NR will generate slope and aspect conditions that are not constructible and need to be adjusted.

- Slopes steeper than 3:1 (H:V) should be reduced to 3:1 or less while maintaining ridge break lines and channel flow lines, if possible.

- Sharp breaks (up to $90^{\circ}$ ) need to be smoothed to reflect typical turn radii of heavy equipment while maintaining ridge breaks and channel flow lines, if possible.

- Channel parameters such as "A" channel length and meander channel sinuosity and crosssectional area should be adjusted for construction constraints of heavy equipment.

- NR does not optimize earthwork volumes. The design engineer needs to be conscious of this fact and seek to develop cost-effective designs.

\section{Control and Retention Structures}

NR does not incorporate retention and/or surface drainage control structures. Such structures are often necessary for steep terrain and for downstream protection. When structures are necessary to achieve channel stability and/or limit peak downstream flow, the NR design should be broken into separate basins with design input reflecting the controlled conditions.

\section{Monitoring}

Ongoing monitoring of geomorphic projects designed with NR is recommended. NR is a relatively new software application that could benefit from construction and performance feedback. Monitoring should include routine inspections of the main and tributary channels for erosion and sediment transport, inspection of drainage control structures, and vegetative cover and diversity.

\section{$\underline{\text { Literature Cited }}$}

Miller, K.A. 2003. Peak-Flow Characteristic of Wyoming Streams, U.S.G.S. Report 03-4107. Walker, S. 2013. Tools to assist in planning and design, Engineering \& Mining Journal, Jan., pp. 34-39. 